Article

\title{
Cyclosporin A Increases Mitochondrial Buffering of Calcium: An Additional Mechanism in Delaying Mitochondrial Permeability Transition Pore Opening
}

\author{
Jyotsna Mishra ${ }^{1}$, Ariea J. Davani ${ }^{1}$, Gayathri K. Natarajan ${ }^{1}$, Wai-Meng Kwok ${ }^{1,2,3,4}$, \\ David F. Stowe $1,2,5,6$ and Amadou K.S. Camara 1,2,4,6,* \\ Department of Anesthesiology, Medical College of Wisconsin, Milwaukee, WI 53226, USA \\ Cardiovascular Center, Medical College of Wisconsin, Milwaukee, WI 53226, USA \\ Department of Pharmacology and Toxicology, Medical College of Wisconsin, Milwaukee, WI 53226, USA \\ Cancer Center, Medical College of Wisconsin, Milwaukee, WI 53226, USA \\ Research Service, Zablocki VA Medical Center, Milwaukee, WI 53295, USA \\ 6 Department of Physiology, Medical College of Wisconsin, Milwaukee, WI 53226, USA \\ * Correspondence: aksc@mcw.edu; Tel.: +1-(414)-955-5624
}

Received: 6 July 2019; Accepted: 3 September 2019; Published: 7 September 2019

\begin{abstract}
Regulation of mitochondrial free $\mathrm{Ca}^{2+}$ is critically important for cellular homeostasis. An increase in mitochondrial matrix free $\mathrm{Ca}^{2+}$ concentration $\left(\left[\mathrm{Ca}^{2+}\right]_{\mathrm{m}}\right)$ predisposes mitochondria to opening of the permeability transition pore (mPTP). Opening of the pore can be delayed by cyclosporin A (CsA), possibly by inhibiting cyclophilin D (Cyp D), a key regulator of mPTP. Here, we report on a novel mechanism by which CsA delays MPTP opening by enhanced sequestration of matrix free $\mathrm{Ca}^{2+}$. Cardiac-isolated mitochondria were challenged with repetitive $\mathrm{CaCl}_{2}$ boluses under $\mathrm{Na}^{+}$-free buffer conditions with and without CsA. CsA significantly delayed mPTP opening primarily by promoting matrix $\mathrm{Ca}^{2+}$ sequestration, leading to sustained basal $\left[\mathrm{Ca}^{2+}\right]_{\mathrm{m}}$ levels for an extended period. The preservation of basal $\left[\mathrm{Ca}^{2+}\right]_{\mathrm{m}}$ during the $\mathrm{CaCl}_{2}$ pulse challenge was associated with normalized $\mathrm{NADH}$, matrix $\mathrm{pH}\left(\mathrm{pH}_{\mathrm{m}}\right)$, and mitochondrial membrane potential $\left(\Delta \Psi_{\mathrm{m}}\right)$. Notably, we found that in $\mathrm{PO}_{4}{ }^{3-}\left(\mathrm{P}_{\mathrm{i}}\right)$-free buffer condition, the CsA-mediated buffering of $\left[\mathrm{Ca}^{2+}\right]_{\mathrm{m}}$ was abrogated, and mitochondrial bioenergetics variables were concurrently compromised. In the presence of CsA, addition of $P_{i}$ just before pore opening in the $P_{i}$-depleted condition reinstated the $\mathrm{Ca}^{2+}$ buffering system and rescued mitochondria from mPTP opening. This study shows that CsA promotes $\mathrm{P}_{\mathrm{i}}$-dependent mitochondrial $\mathrm{Ca}^{2+}$ sequestration to delay mPTP opening and, concomitantly, maintains mitochondrial function.
\end{abstract}

Keywords: cyclosporin A; mitochondria calcium buffering; mitochondria bioenergetics; mitochondria permeability transition pore; inorganic phosphate

\section{Introduction}

Regulation of intra-mitochondrial free calcium $\left(\left[\mathrm{Ca}^{2+}\right]_{\mathrm{m}}\right)$ is critical in cardiac physiology and pathophysiology. Under physiological conditions, a moderate increase in $\left[\mathrm{Ca}^{2+}\right]_{\mathrm{m}}$ is believed to stimulate key enzymes of the Krebs cycle and oxidative phosphorylation and to drive mitochondrial ATP production to match cellular energy demand $[1,2]$. In contrast, a pathological increase in $\left[\mathrm{Ca}^{2+}\right]_{\mathrm{m}}$ causes opening of the mitochondrial permeability transition pore (mPTP), a key factor in initiation of cell death $[3,4]$. Pathophysiological dysregulation of $\left[\mathrm{Ca}^{2+}\right]_{\mathrm{m}}$ is a primary mediator in cardiac ischemia and reperfusion (IR) injury, as $\mathrm{Ca}^{2+}$ overloading can lead to apoptosis [5-7].

$\left[\mathrm{Ca}^{2+}\right]_{\mathrm{m}}$ is regulated by a dynamic balance between mitochondrial $\mathrm{Ca}^{2+}$ uptake, intra-mitochondrial $\mathrm{Ca}^{2+}$ buffering, and mitochondrial $\mathrm{Ca}^{2+}$ release. Mitochondrial $\mathrm{Ca}^{2+}$ uptake 
is mediated primarily through the mitochondrial $\mathrm{Ca}^{2+}$ uniporter (MCU) [8-10], and is controlled by the large membrane potential $\left(\Delta \Psi_{\mathrm{m}}:-180\right.$ to $-200 \mathrm{mV}$ ) across the inner mitochondrial membrane (IMM). The $\Delta \Psi_{\mathrm{m}}$ in turn is generated by the flow of electrons and proton pumping along the respiratory chain complexes [11]. When $\left[\mathrm{Ca}^{2+}\right]_{\mathrm{m}}$ increases, this depolarizes $\Delta \Psi_{\mathrm{m}}$, which is compensated by enhanced $\mathrm{H}^{+}$pumping/extrusion to alkalinize the matrix. Therefore, powerful, dynamic buffering of matrix $\mathrm{pH}$ $\left(\mathrm{pH}_{\mathrm{m}}\right)$ and $\mathrm{Ca}^{2+}$ are required to enable sufficient recovery of $\Delta \Psi_{\mathrm{m}}$ and to avoid overloading the matrix with a high $\left[\mathrm{Ca}^{2+}\right]$. Inorganic phosphate $\left(\mathrm{P}_{\mathrm{i}}\right)$ has been recognized as a major player in maintaining the trans-matrix $\mathrm{pH}$ gradient when accompanied by the effective cotransport of $\mathrm{H}^{+}$[12] and buffering of matrix $\mathrm{Ca}^{2+}$ through the formation of amorphous calcium phosphate $\left(\mathrm{Ca}-\mathrm{P}_{\mathrm{i}}\right)$ granules [13-15]. The $\mathrm{Ca}-\mathrm{P}_{\mathrm{i}}$ buffer system sets the free $\mathrm{Ca}^{2+}$ at a steady-state level, enabling greater mitochondrial $\mathrm{Ca}^{2+}$ loading without impeding the $\mathrm{Ca}^{2+}$ uptake and affecting the efflux system [16-18]. The efflux systems that regulate $\left[\mathrm{Ca}^{2+}\right]_{\mathrm{m}}$ are the $\mathrm{Na}^{+} / \mathrm{Ca}^{2+}$ exchanger (NCLX) [17], and the putative $\mathrm{Na}^{+}$-independent $\mathrm{Ca}^{2+}$ exchanger/ $\mathrm{Ca}^{2+}$-hydrogen exchanger (CHE) [19]. Any disruption in the uptake, and or impairment in the buffering or efflux of $\mathrm{Ca}^{2+}$ would disrupt the delicate balance of the $\left[\mathrm{Ca}^{2+}\right]_{\mathrm{m}}$ and lead to impaired bioenergetics and to opening of the MPTP [3,4].

The opening of the high conductance mPTP channel is associated with a high degree of mitochondrial swelling, dissipation of $\Delta \Psi_{\mathrm{m}}$, uncoupling of oxidative phosphorylation, membrane rupture and release of sequestered $\mathrm{Ca}^{2+}$, metabolites, and apoptotic signaling molecules [20-23]. Although the molecular components of the MPTP and its regulation remain largely unclear, cyclophilin $\mathrm{D}($ Cyp D) is the only unambiguously recognized regulatory component of the mPTP. Cyp D is a mitochondrial matrix peptidyl-prolyl cis-trans isomerase (PPIase) that is translocated to the IMM during high matrix $\mathrm{Ca}^{2+}$ conditions; Cyp D is proposed to facilitate conformational changes in the putative MPTP core proteins thereby regulating pore opening [24-26].

Adenine nucleotides (AdN: ATP and ADP) have been implicated in the inhibition of $\mathrm{Ca}^{2+}$-dependent mPTP opening $[27,28]$. A previous study from our laboratory suggested that matrix AdN modulate $\left[\mathrm{Ca}^{2+}\right]_{\mathrm{m}}$, potentially by increased buffering of $\left[\mathrm{Ca}^{2+}\right]_{\mathrm{m}}[29]$. Oligomycin $(\mathrm{OMN})$, an $\mathrm{F}_{0} \mathrm{~F}_{1}$-ATP synthase inhibitor, influences the $\mathrm{AdN}$ (ATP/ADP) pool, and has been shown to modulate mPTP opening [30]. Cyclosporin A (CsA), a potent mPTP inhibitor is also believed to suppress pore opening by inhibiting matrix Cyp D, thereby preventing the Cyp D-induced conformational changes in $\mathrm{mPTP}$ core proteins [31,32]. CsA has long been known to desensitize mPTP from early opening during $\mathrm{Ca}^{2+}$ challenges by impeding $\mathrm{Ca}^{2+}$ interaction with Cyp D; however, the direct effects of CsA on the $\left[\mathrm{Ca}^{2+}\right]_{\mathrm{m}}$ buffering system have not been investigated systematically. It is worth noting that in a previous study from Chalmers and Nicholls [14], it was proposed that CsA enhances the $\mathrm{Ca}^{2+}$ loading capacity of mitochondria without changing the relationship between free $\left[\mathrm{Ca}^{2+}\right]_{\mathrm{m}}$ and total $\left[\mathrm{Ca}^{2+}\right]_{\mathrm{m}}$ during continuous $\mathrm{Ca}^{2+}$ infusion in isolated rat liver and brain mitochondria. Altschuld et al. [33] proposed that CsA increases mitochondrial $\mathrm{Ca}^{2+}$ influx and reduces its efflux. Later, Wei et al. [34] demonstrated that although CsA had no effect on MCU activity, it inhibited NCLX activity at higher concentrations. Altogether, these findings raise important questions about how CsA delays $\mathrm{Ca}^{2+}$-induced $\mathrm{mPTP}$ opening while increasing net $\left[\mathrm{Ca}^{2+}\right]_{\mathrm{m}}$ accumulation. Our study sought to answer these questions by (i) examining the effect of $\mathrm{CsA}$ during repeated $\mathrm{CaCl}_{2}$ challenges over an extended time-period on mitochondrial $\mathrm{Ca}^{2+}$ buffering, and (ii) by examining the underlying changes in bioenergetics during excessive $\mathrm{Ca}^{2+}$ overload.

To address our objective, we investigated systematically the effect of CsA on mitochondrial $\mathrm{Ca}^{2+}$ buffering and compared its effect with a known matrix buffering component, the AdN pool $(\mathrm{OMN}+\mathrm{ADP})$, by monitoring $\left[\mathrm{Ca}^{2+}\right]_{\mathrm{e}},\left[\mathrm{Ca}^{2+}\right]_{\mathrm{m}}$, and key mitochondrial bioenergetics variables, $\Delta \Psi_{\mathrm{m}}$, $\mathrm{pH}_{\mathrm{m}}$, and $\mathrm{NADH}$ (redox state), under conditions of repeated $\mathrm{Ca}^{2+}$ loading. Furthermore, we determined the effect of CsA on the rescue of buffering capability and bioenergetics of failing mitochondria just before mPTP opening. We found that CsA enhanced the sequestration of mitochondrial $\mathrm{Ca}^{2+}$, maintained $\left[\mathrm{Ca}^{2+}\right]_{\mathrm{m}}$ at a steady-state level, and markedly delayed mPTP opening. In addition, CsA preserved $\Delta \Psi_{\mathrm{m}}, \mathrm{NADH}$, and $\mathrm{pH}_{\mathrm{m}}$ during $\mathrm{CaCl}_{2}$ bolus challenges. However, in the absence of $\mathrm{P}_{\mathrm{i}}$, this 
CsA-induced matrix $\mathrm{Ca}^{2+}$ sequestration was abrogated, and in turn led to the early mPTP opening. The results described herein reveal a novel way by which CsA modulates matrix $\mathrm{Ca}^{2+}$ sequestration to maintain $\left[\mathrm{Ca}^{2+}\right]_{\mathrm{m}}$, despite increased $\mathrm{Ca}^{2+}$ loading. CsA-mediated $\mathrm{Ca}^{2+}$ sequestration is likely achieved via a $\mathrm{P}_{\mathrm{i}}$-dependent $\left[\mathrm{Ca}^{2+}\right]_{\mathrm{m}}$ buffering system that delays $\mathrm{Ca}^{2+}$-induced mPTP opening.

\section{Materials and Methods}

\subsection{Materials}

All chemical reagents were purchased from Sigma-Aldrich (St. Louis, MO, USA), unless stated otherwise. Fluorescent probes Fura- $4 \mathrm{~F}$, Fura- $4 \mathrm{~F}^{\mathrm{AM}}$, tetramethylrhodamine methyl ester perchlorate (TMRM) and 2', $7^{\prime}$-Bis-(2-Carboxyethyl)-5-(and-6)-carboxyfluorescein, acetoxymethyl ester (BCECF ${ }^{\mathrm{AM}}$ ) were purchased from Life Technologies (Eugene, OR, USA).

\subsection{Animals}

Albino Hartley guinea pigs of both sexes weighing between 250 to $350 \mathrm{~g}$ were procured from Kuiper Rabbit Farm (Gary, IN, USA). All procedures were carried out in accordance with the National Institutes of Health (NIH) Guide for the Care and Use of Laboratory Animals (NIH Publication No. 85-23, revised 1996) and were approved by the Institutional Animal Care and Use Committee of the Medical College of Wisconsin.

\subsection{Mitochondria Isolation}

Mitochondria were isolated from guinea pig hearts as described previously [29,35,36]. Briefly, the guinea pig was anesthetized with an intraperitoneal injection of $30 \mathrm{mg}$ ketamine plus 700 units of heparin, for anticoagulation, and the heart was rapidly excised and minced in ice-cold isolation buffer containing $200 \mathrm{mM}$ mannitol, $50 \mathrm{mM}$ sucrose, $5 \mathrm{mM} \mathrm{KH}{ }_{2} \mathrm{PO}_{4}, 5 \mathrm{mM}$ MOPS, $1 \mathrm{mM}$ EGTA, and $0.1 \%$ bovine serum albumin (BSA) at pH 7.15 (adjusted with $\mathrm{KOH}$ ). The suspension was homogenized at low speed for $20 \mathrm{~s}$ in ice-cold isolation buffer containing $5 \mathrm{U} / \mathrm{mL}$ protease (from Bacillus licheniformis) and the homogenate was centrifuged at $8000 \times g$ for $10 \mathrm{~min}$. The supernatant was discarded, and the pellet was suspended in $25 \mathrm{~mL}$ isolation buffer, and centrifuged at $850 \times g$ for $10 \mathrm{~min}$. The supernatant was centrifuged further at $8000 \times g$ to yield the final mitochondrial pellet, which was suspended in isolation buffer and kept on ice until experimentation. All isolation procedures were performed at $4{ }^{\circ} \mathrm{C}$ and all experiments were conducted at room temperature. Protein concentration was determined by the Bradford method and the final mitochondrial suspension was adjusted to $12.5 \mathrm{mg}$ protein $/ \mathrm{mL}$ with isolation buffer.

The functional integrity of mitochondria was determined by the respiratory control index (RCI) as described before [29,37]. Mitochondria were energized with pyruvic acid (PA, $0.5 \mathrm{mM}$; $\mathrm{pH} 7.15$, adjusted with $\mathrm{KOH})$ followed by ADP $(250 \mu \mathrm{M})$ addition. RCI was defined as the ratio of state 3 (after added ADP) to state 4 respiration (after complete phosphorylation of the added ADP). Only mitochondrial preparations with RCIs $\geq 10$ were used to conduct further experiments.

\subsection{Experimental Groups and Protocols}

Two protocols (Protocol A and Protocol B) were used to assess the effect of CsA and AdN on mitochondrial $\mathrm{Ca}^{2+}$ handling and bioenergetics in normal and $\mathrm{Ca}^{2+}$-overloaded mitochondria, as shown in Figure 1. Protocol A investigated the ability of CsA and AdN to modulate mitochondrial $\mathrm{Ca}^{2+}$ handling and delay mPTP opening. To further substantiate CsA-mediated buffering of matrix $\mathrm{Ca}^{2+}$, Protocol B was designed to test the effectiveness of CsA and AdN on rescuing a failing mitochondrial $\mathrm{Ca}^{2+}$ buffering system from imminent mPTP opening. There were five experimental groups: vehicle (DMSO), CsA, ADP, OMN, and OMN+ADP. Experiments were also conducted in the presence of deionized $\mathrm{H}_{2} \mathrm{O}$ as another vehicle (not shown). Each group was subjected to two different experimental protocols (Protocol A and Protocol B) that differed in the order of treatment and addition of $\mathrm{CaCl}_{2}$ boluses to the mitochondrial suspension in experimental buffer. 


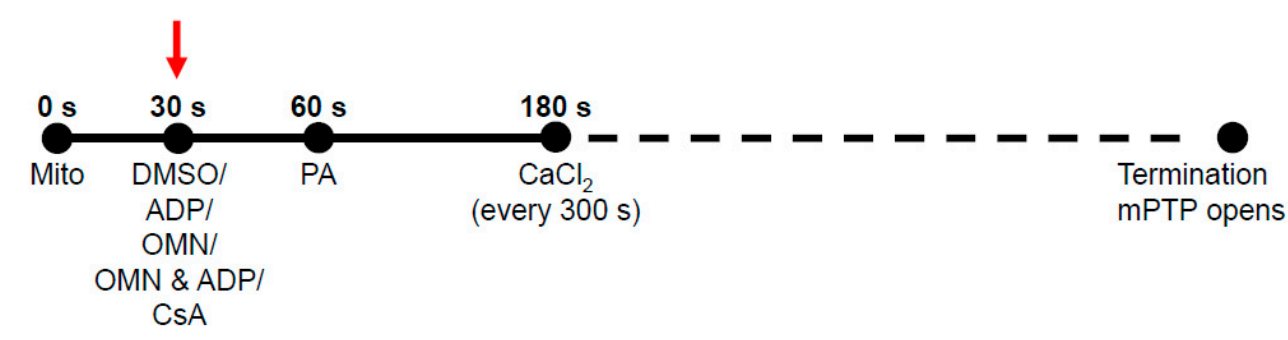

B

Protocol B: Rescue

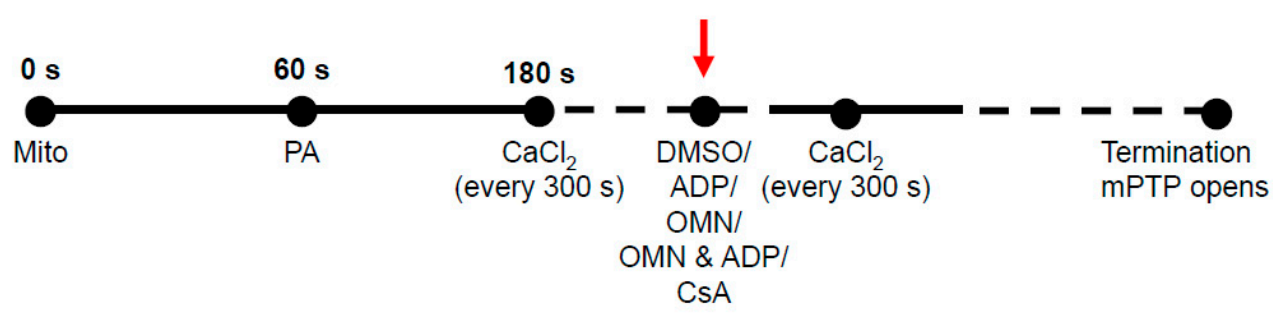

Figure 1. Schema of experimental timeline used to study the effect of Cyclosporin A (CsA) and adenine nucleotide $(\mathrm{AdN})$ on mitochondrial $\mathrm{Ca}^{2+}$ handling and bioenergetics during repeated $\mathrm{CaCl}_{2}$ pulses. (A) In Protocol $\mathrm{A}$, at $\mathrm{t}=0 \mathrm{~s}$, mitochondria (mito, $0.5 \mathrm{mg}$ ) were added to the $\mathrm{Na}^{+}$-free experimental buffer solution. The mitochondrial suspension was exposed to $0.5 \mu \mathrm{M}$ CsA, $250 \mu \mathrm{M}$ ADP, $10 \mu \mathrm{M}$ oligomycin $(\mathrm{OMN})$, or a combination of OMN+ADP at $\mathrm{t}=30 \mathrm{~s}$. Pyruvic acid $(\mathrm{PA}, 0.5 \mathrm{mM})$, was added at $\mathrm{t}=60 \mathrm{~s}$ to energize mitochondria (state 2). At $\mathrm{t}=180 \mathrm{~s}, 20 \mu \mathrm{M}$ of $\mathrm{CaCl}_{2}$ was added, followed by sequential additions of $20 \mu \mathrm{M} \mathrm{CaCl}_{2}$ at every $300 \mathrm{~s}$ intervals until mPTP (mitochondrial permeability transition pore) opened or no further $\mathrm{Ca}^{2+}$ uptake was observed. (B) In Protocol B, the mitochondrial suspension was exposed to similar treatments as in Protocol A, but given after the last consecutive $\mathrm{CaCl}_{2}$ bolus preceding the imminent onset of mPTP opening.

Delayed opening of mPTP (Protocol A): At $t=0 \mathrm{~s}$, the experiment was initiated by suspending $0.5 \mathrm{mg}$ of isolated mitochondria into the experimental buffer containing $130 \mathrm{mM} \mathrm{KCl}, 5 \mathrm{mM} \mathrm{K}_{2} \mathrm{HPO}_{4}$, $20 \mathrm{mM}$ MOPS, $1 \mathrm{mM}$ EGTA, 0.1\% BSA, and EGTA $\sim 0.036-0.040 \mu \mathrm{M}$ at pH 7.15 (adjusted with $\mathrm{KOH}$ ). At $t=30 \mathrm{~s}$, mitochondria were treated with DMSO $(1 \mu \mathrm{M}), \mathrm{ADP}(250 \mu \mathrm{M}), \mathrm{OMN}(10 \mu \mathrm{M}), \mathrm{OMN}+\mathrm{ADP}$ or CsA $(0.5 \mu \mathrm{M})$; at $\mathrm{t}=60 \mathrm{~s}$, mitochondria were energized with PA $(0.5 \mathrm{mM})$. At $\mathrm{t}=180 \mathrm{~s}, \mathrm{CaCl}_{2}$ bolus (20 $\mu \mathrm{M}$ final concentration) was added and subsequent $\mathrm{CaCl}_{2}$ boluses added at 5 min intervals until pore opening (Figure 1A). Note that all experiments were conducted under state 2 conditions, except in the ADP-and OMN+ADP-treated groups.

Rescue of mitochondria from mPTP opening (Protocol B): The mitochondrial suspension was exposed to repetitive boluses of $\mathrm{CaCl}_{2}(20 \mu \mathrm{M})$ as described in Protocol A; rescue of mitochondria from mPTP opening with the different treatments was carried out at $1 \mathrm{~min}$ of the last $\mathrm{CaCl}_{2}$ bolus in which mitochondria $\mathrm{Ca}^{2+}$ uptake was observed before pore opening (Figure 1B). The onset of mPTP opening was predicted based on calcium retention capacity (CRC) of the DMSO (control)-treated group for each day's experiment. The pulse preceding mPTP opening observed in the control was the pulse chosen for targeted intervention in all subsequent experiments. In all experiments, extrusion of $\mathrm{Ca}^{2+}$ via the $\mathrm{Na}^{+} / \mathrm{Ca}^{2+}$ exchanger (NCLX) was prevented by conducting all the experiments in $\mathrm{Na}^{+}$-free conditions. That is, the respiration buffer, mitochondrial substrates, and all reagents/drugs were $\mathrm{Na}^{+}$-free to prevent activation of the NCLX. Some experiments were conducted in the presence of $10 \mu \mathrm{M}$ CGP 37157 (Tocris Bioscience), an NCLX inhibitor, which ascertained there was no potential $\mathrm{Na}^{+}$contamination in the respiration buffer from other sources $[35,38,39]$. 


\subsection{Mitochondrial Function Measurements}

Fluorescence spectrophotometry (Qm-8, Photon Technology International, Horiba, Birmingham, NJ, USA) was used to measure mitochondrial function, including mitochondria extra- and intra-matrix free $\left[\mathrm{Ca}^{2+}\right]\left(\left[\mathrm{Ca}^{2+}\right]_{\mathrm{e}}\right.$ and $\left[\mathrm{Ca}^{2+}\right]_{\mathrm{m}}$, respectively), $\Delta \Psi_{\mathrm{m}}$, redox state $(\mathrm{NADH})$, and $\mathrm{pH}$. Fura-4F penta-potassium salt $\left(1 \mu \mathrm{M}\right.$, Invitrogen ${ }^{\mathrm{TM}}$, Eugene, OR) was used to measure $\left[\mathrm{Ca}^{2+}\right]_{\mathrm{e}}$. For $\left[\mathrm{Ca}^{2+}\right]_{\mathrm{m}}$ measurements, mitochondria were incubated with Fura-4F AM ( $5 \mu \mathrm{M}$, Invitrogen ${ }^{\mathrm{TM}}$, Eugene, OR) for $30 \mathrm{~min}$ at room temperature $\left(25^{\circ} \mathrm{C}\right)$ followed by a final spin and resuspension to remove any residual dye. $\Delta \Psi_{\mathrm{m}}$ was assessed using the cationic lipophilic dye TMRM $\left(1 \mu \mathrm{M}\right.$, Invitrogen ${ }^{\mathrm{TM}}$, Eugene, OR, USA) in a ratiometric excitation approach [40]. NADH was measured by tissue autofluorescence, and matrix $\mathrm{pH}\left(\mathrm{pH}_{\mathrm{m}}\right)$ was assessed by incubating mitochondria in $5 \mu \mathrm{M} \mathrm{BCECF}^{\mathrm{AM}}$ (Invitrogen, Carlsbad, CA, USA) for $30 \mathrm{~min}$ at room temperature $\left(25^{\circ} \mathrm{C}\right)$ followed by a final spin and resuspension $[29,35,38,39]$.

\subsection{Measurements of Free $\mathrm{Ca}^{2+}$}

Quantification of $\left[\mathrm{Ca}^{2+}\right]_{\mathrm{e}}$ and $\left[\mathrm{Ca}^{2+}\right]_{\mathrm{m}}$ were made using the fluorescent $\mathrm{Ca}^{2+}$ indicator probe Fura-4F with dual-excitation wavelengths $\left(\lambda_{\mathrm{ex}}\right)$ at $340 / 380 \mathrm{~nm}$ and a single emission wavelength $\left(\lambda_{\mathrm{em}}\right)$ at $510 \mathrm{~nm}$. $\mathrm{Ca}^{2+}$ fluorescent intensities with Fura-4F are not influenced by background noise (e.g., NADH autofluorescence), so a background subtraction was unnecessary [38]. Fura-4F fluorescence ratios $\left(\mathrm{F}_{340} / \mathrm{F}_{380}\right)$ were used to calculate $\left[\mathrm{Ca}^{2+}\right]$ using the equation described by Grynkiewicz: [41].

$$
\left[\mathrm{Ca}^{2+}\right]=\mathrm{K}_{\mathrm{d}} \frac{\mathrm{S}_{\mathrm{f} 2}}{\mathrm{~S}_{\mathrm{b} 2}} \frac{\left(\mathrm{R}-\mathrm{R}_{\min }\right)}{\left(\mathrm{R}_{\max }-\mathrm{R}\right)} .
$$

The $\mathrm{K}_{\mathrm{d}}$ value for Fura-4F binding to $\mathrm{Ca}^{2+}$ is $890 \mathrm{nM}$, which was described by us previously [38]. $\mathrm{R}$ is the ratio of the fluorescence intensities at $\lambda_{\mathrm{ex}} 340$ and $380 \mathrm{~nm}, \mathrm{~S}_{\mathrm{f} 2} / \mathrm{S}_{\mathrm{b} 2}$ is the ratio of fluorescence intensities measured at $\lambda_{\text {ex }} 380 \mathrm{~nm}$ in $\mathrm{Ca}^{2+}$-free $(\mathrm{f}) / \mathrm{Ca}^{2+}$-saturated $\left(\mathrm{Ca}^{2+}\right.$-bound, b) conditions. $\mathrm{R}_{\min }\left(\mathrm{Ca}^{2+}\right.$-free $)$ and $\mathrm{R}_{\max }\left(\mathrm{Ca}^{2+}\right.$-saturated) are $\mathrm{R}$ values for Fura $4 \mathrm{~F}$, carried out after $\mathrm{mPTP}$ opening, adding $1 \mathrm{mM}$ $\mathrm{CaCl}_{2}$, followed by $10 \mathrm{mM}$ EGTA, pH 7.1. The free $\left[\mathrm{Ca}^{2+}\right]$ in the buffer was calculated using an online version of MaxChelator program (http://www.stanford.edu/ \{\}cpatton/maxc.html) and accordingly, a standard curve was generated for the Fura-4F signal to the free $\left[\mathrm{Ca}^{2+}\right]$ in the experimental solution by fitting to the Grynkiewicz equation, as described above in Equation 1 [41].

\subsection{Calculation of Mitochondrial $\mathrm{Ca}^{2+}$ Buffering Capacity}

The ability of mitochondria to sequester $\mathrm{Ca}^{2+}$ is an index of its $\mathrm{Ca}^{2+}$ loading capacity, without altering mitochondrial function. Here we calculated mitochondrial $\mathrm{Ca}^{2+}$ buffering capacity $\left(\mathrm{m} \beta_{\mathrm{Ca}}\right)$ using the model described by Bazil et al. [42]. Briefly, experimental data for extra-and intra-matrix $\mathrm{Ca}^{2+}$ were fit with smooth trend curves satisfying the equation:

$$
y(t)=p_{1}+p_{2} e^{\frac{\left(t-p_{3}\right)}{p_{4}}}+p_{5} t
$$

where $y(t)$ was either $\left[\mathrm{Ca}^{2+}\right]_{e}$ or $\left[\mathrm{Ca}^{2+}\right]_{\mathrm{m}}$ at any given time, $\mathrm{t}$. Global trend-fits were performed in MATLAB (Mathworks, Inc., MA) and parameters $\mathrm{p}_{1}$ (offset value), $\mathrm{p}_{2}$ (pre = exponential constant), $\mathrm{p}_{3}$ (time lag), $\mathrm{p}_{4}$ (decay time constant), and $\mathrm{p}_{5}$ (steady-state slope) were estimated and optimized using the lsqnonlin and fmincon functions.

Mitochondrial $\mathrm{Ca}^{2+}$ buffering capacity for the second $\mathrm{Ca}^{2+}$ pulse (a cumulative of $40 \mu \mathrm{M}$ added $\mathrm{Ca}^{2+}$ ) was then calculated [42] as:

$$
\mathrm{m} \beta_{\mathrm{Ca}}=-\beta_{\mathrm{Ca}, \mathrm{e}} \mathrm{V}_{\mathrm{r}} \frac{\mathrm{d}\left[\mathrm{Ca}^{2+}\right]_{\mathrm{e}}}{\mathrm{dt}} / \frac{\mathrm{d}\left[\mathrm{Ca}^{2+}\right]_{\mathrm{m}}}{\mathrm{dt}},
$$

where, $\mathrm{m} \beta_{\mathrm{Ca}}$, is the intra-mitochondrial $\mathrm{Ca}^{2+}$ buffering power, $\beta_{\mathrm{Ca}, \mathrm{e}}$ is the extra-mitochondrial $\mathrm{Ca}^{2+}$ buffering power determined by: 


$$
\beta_{\mathrm{Ca}, \mathrm{e}}=1+\frac{\partial[\mathrm{CaEGTA}]_{\mathrm{e}}}{\partial\left[\mathrm{Ca}^{2+}\right]_{\mathrm{e}}} .
$$

$\mathrm{Vr}$ is the volume ratio of the extra-mitochondrial space and matrix space $(\sim 2000), \mathrm{d}\left[\mathrm{Ca}^{2+}\right]_{\mathrm{e}} / \mathrm{dt}$ and $\mathrm{d}\left[\mathrm{Ca}^{2+}\right]_{\mathrm{m}} / \mathrm{dt}$ are the rates of change of extra-and intra-mitochondrial free $\left[\mathrm{Ca}^{2+}\right]$, respectively. $\mathrm{d}\left[\mathrm{Ca}^{2+}\right]_{\mathrm{e}} / \mathrm{dt}$ and $\mathrm{d}\left[\mathrm{Ca}^{2+}\right]_{\mathrm{m}} / \mathrm{dt}$ were estimated by evaluating the analytical derivative of Equation (2) using parameter estimates obtained from the trend fits [42].

Trend fits for data in Figure S4 were performed in Origin 2017 (OriginLab Corporation, Northampton, MA, USA).

\subsection{Measurement of $\Delta \Psi_{m}$, Redox State (NADH) and Matrix $p H$}

Membrane potential was assessed by the dual-excitation ratiometric approach using the fluorescent dye, TMRM, as described by Scaduto and Grotyohann [40] and in our published work [35,38,39]. Fluorescence changes were determined by two excitations, $\lambda_{\text {ex }} 546$ and $573 \mathrm{~nm}$, and a single emission $\lambda_{\text {em }} 590 \mathrm{~nm}$. The calculated ratio of $\lambda$ ex $573 / 546$ is proportional to $\Delta \Psi_{\mathrm{m}}$ and has the advantage of a broader dynamic range when compared to a single wavelength technique. Changes in mitochondrial redox state $(\mathrm{NADH})$ were determined by autofluorescence (i.e., by exciting the energized mitochondria at $\lambda_{\mathrm{ex}} 350 \mathrm{~nm}$ and collecting data at $\lambda_{\mathrm{em}} 456 \mathrm{~nm}$ ). An increase in the signal reflects an increase in the redox ratio of $\mathrm{NADH}$ to $\mathrm{NAD}^{+}$(i.e., a shift to a more reduced state). Matrix $\mathrm{pH}$ was assessed using $\operatorname{BCECF}^{\mathrm{AM}}(5 \mu \mathrm{M})$ at $\lambda_{\mathrm{ex}} 504 \mathrm{~nm}$ and $\lambda_{\mathrm{em}} 530 \mathrm{~nm}$. This fluorescent probe emits less fluorescence in an acidic environment, thus a decrease in signal indicates matrix acidification and an increase in signal indicates matrix alkalization [29].

\subsection{Depletion of Endogenous Mitochondrial Phosphate}

Given the important role of $P_{i}$ in the mitochondrial $\mathrm{Ca}^{2+}$ buffering system $[14,29]$, we tested the effect of $\mathrm{P}_{\mathrm{i}}$ in CsA-induced mitochondrial $\mathrm{Ca}^{2+}$ buffering. Isolated cardiac mitochondria were depleted of endogenous $P_{i}$ by pre-incubating mitochondria for $10 \mathrm{~min}$ at room temperature with 0.75 units $/ \mathrm{mL}$ hexokinase, $1 \mathrm{mM}$ glucose, $0.5 \mathrm{mM} \mathrm{ADP}, 1 \mathrm{mM} \mathrm{MgCl}_{2}$, and $5 \mathrm{mM} \mathrm{PA}$, as previously described [14,43,44].

\subsection{Statistical Analyses}

Data were transferred from PTI FelixGX (Version 3) into Microsoft ${ }^{\circledR}$ Excel $^{\circledR}$ (2007). An unpaired Student's t-test was used to evaluate significant differences between means of CsA-treated versus DMSO- and AdN-treated groups on specific variables $\left(\left[\mathrm{Ca}^{2+}\right]_{\mathrm{m}},\left[\mathrm{Ca}^{2+}\right]_{\mathrm{e}}, \Delta \Psi_{\mathrm{m}}, \mathrm{NADH}\right.$, or $\left.\mathrm{pH}_{\mathrm{m}}\right)$ in both Protocols A and B. The final data of a specific variable were expressed as mean \pm standard error (SE) over at least 4 replicates of the same variable $(n=4)$. Comparisons within and between groups were performed by one-way ANOVA (analysis of variance) with Tukey's post-hoc test to examine differences among individual groups. $p<0.05$ (two-tailed) was considered significant. See Figure legends for statistical notations.

\section{Results}

\subsection{Effect of CsA on Extra-Matrix Free $\left[\mathrm{Ca}^{2+}\right]$}

To determine the effect of $\mathrm{CsA}$ on matrix $\mathrm{Ca}^{2+}$ uptake, we measured $\left[\mathrm{Ca}^{2+}\right]_{\mathrm{e}}$ during repetitive additions of $20 \mu \mathrm{M} \mathrm{CaCl}_{2}$ boluses at $5 \mathrm{~min}$ (300 s) intervals to allow characterization of the detailed kinetics of steady-state $\mathrm{Ca}^{2+}$ dynamics (influx and buffering). Figure 2 shows the dynamics of $\left[\mathrm{Ca}^{2+}\right]_{\mathrm{e}}$ during $\mathrm{CaCl}_{2}$ pulse challenges, with different treatments. Panels $\mathrm{A}, \mathrm{B}, \mathrm{C}$ and panels D, E, F depict the $\mathrm{Ca}^{2+}$ dynamics profile using Protocols $\mathrm{A}$ and $\mathrm{B}$, respectively. Each panel consists of five traces representing different treatment groups (DMSO, ADP, OMN, OMN+ADP, and CsA) in the presence of approximately $40 \mu \mathrm{M}$ EGTA (carried over from the isolation buffer). In response to each $\mathrm{CaCl}_{2}$ pulse, an increase in Fura- $4 \mathrm{~F}$ fluorescence intensity was observed, which then returned to a baseline; the 
steady-state (ss) level is marked by the flat response as mitochondria take up and sequester the added $\mathrm{Ca}^{2+}$. The opening of mPTP is evident by cessation of mitochondrial $\mathrm{Ca}^{2+}$ uptake and a sharp rise in the extra-matrix dye fluorescent intensity. $\mathrm{Ca}^{2+}$ concentrations were determined from the fluorescence ratios using Equation (1).

Protocol A: Pre-exposure

A

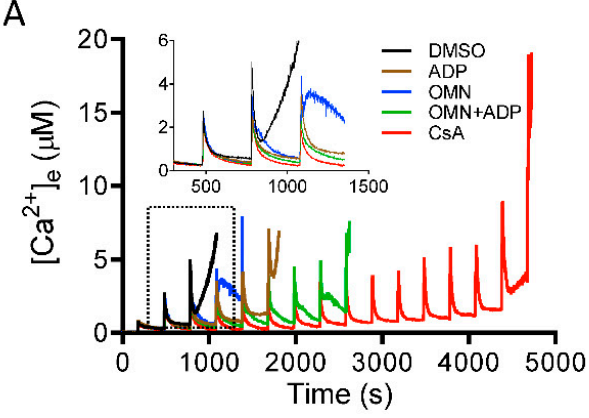

B

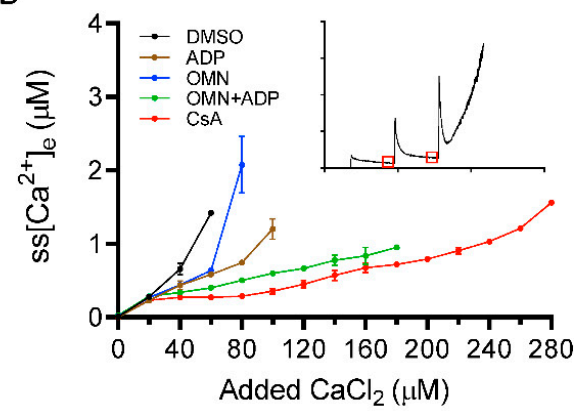

C

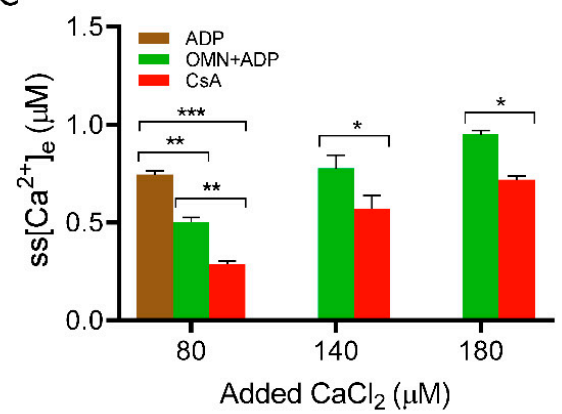

Protocol B: Rescue

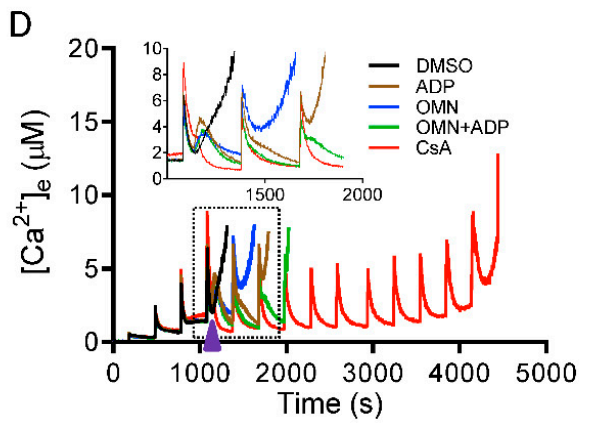

E

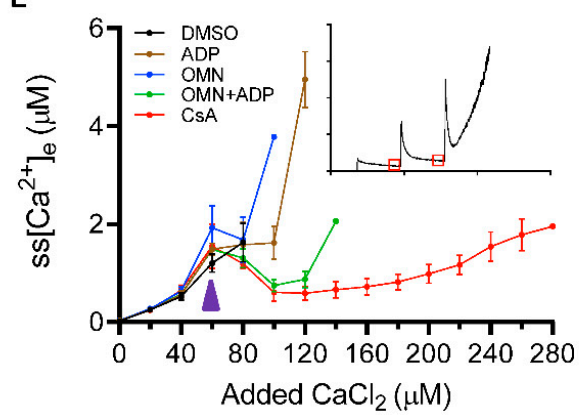

$\mathrm{F}$

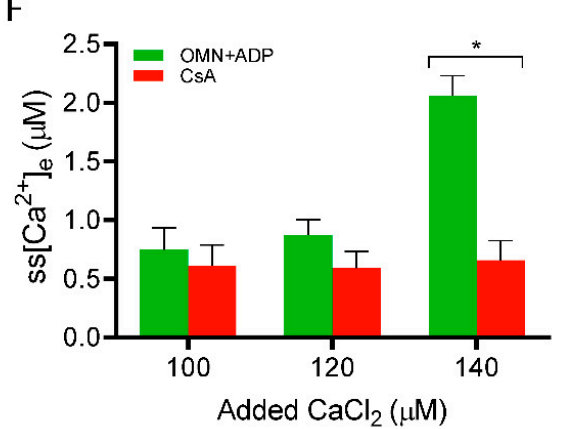

Figure 2. Effect of CsA and AdN on extra-mitochondrial calcium $\left(\left[\mathrm{Ca}^{2+}\right]_{e}\right)$ dynamics. Mitochondrial $\mathrm{Ca}^{2+}$ uptake and buffering for each of the treatment groups: DMSO (control; black trace), CsA (red trace), ADP (brown trace), OMN (blue trace), or OMN+ADP (green trace) are shown using the protocols depicted in Figure 1. Mitochondrial suspension was exposed to $0.5 \mu \mathrm{M}$ CsA, $250 \mu \mathrm{M}$ ADP, $10 \mu \mathrm{M}$ OMN, or OMN+ADP before adding boluses of $20 \mu \mathrm{M} \mathrm{CaCl}_{2}$ (Protocol A; left column). Mitochondrial suspension was exposed to added boluses of $\mathrm{CaCl}_{2}(20 \mu \mathrm{M})$ and rescued mitochondria from mPTP opening (Protocol B; right column) with similar treatments as in Protocol A, at a time point at which it would initiate pore opening. Representative traces show change in extra-matrix free $\mathrm{Ca}^{2+}\left(\left[\mathrm{Ca}^{2+}\right]_{e}\right)$ over time (A), and rescue of mitochondria from mPTP opening (D). Insets $(\mathbf{A}, \mathbf{D})$ show $\mathrm{Ca}^{2+}$ uptake kinetics in detail. Steady-state $\left[\mathrm{Ca}^{2+}\right]_{\mathrm{e}}\left(\mathrm{ss}\left[\mathrm{Ca}^{2+}\right]_{\mathrm{e}}\right), 270 \mathrm{~s}$ after initiation of $\mathrm{Ca}^{2+}$ uptake, plotted as function of added $\mathrm{Ca}^{2+}(20 \mu \mathrm{M})$ every $300 \mathrm{~s}$, in delay of mPTP opening $(\mathbf{B})$, and rescue of mitochondria from mPTP opening (E). Insets $(\mathrm{B}, \mathrm{E})$ indicate the time points at which ss $\left[\mathrm{Ca}^{2+}\right] \mathrm{e}$ was calculated. Quantification of steady-state $\left[\mathrm{Ca}^{2+}\right]_{e}$ after a cumulative of 80,140 , and $180 \mu \mathrm{M} \mathrm{CaCl}_{2}$ during delay of pore opening (C) and cumulative of 100,120, and $140 \mu \mathrm{M} \mathrm{CaCl}_{2}$ during rescue of mitochondria from mPTP opening (F). Error bars represent mean $\pm \operatorname{SEM}\left({ }^{*} p<0.05 ;{ }^{* *} p<0.01 ; * * * p<0.005\right)$. Arrowhead indicates time of addition of DMSO, ADP, OMN, OMN+ADP, or CsA during Protocol B. 
We plotted steady-state $\left[\mathrm{Ca}^{2+}\right]_{\mathrm{e}}\left(\mathrm{ss}\left[\mathrm{Ca}^{2+}\right]_{\mathrm{e}}\right)$ as a function of cumulative added $\mathrm{CaCl}_{2}$ at each pulse (Figure 2B). The detailed dynamics of ss $\left[\mathrm{Ca}^{2+}\right]_{e}$ for the initial four $\mathrm{CaCl}_{2}$ pulses, in each group, are illustrated in the enlarged scale inset (Figure 2A). The exposure of mitochondria to DMSO and $\mathrm{OMN}$, followed by repeated boluses of $\mathrm{CaCl}_{2}$, resulted in a gradual increase in $\mathrm{ss}\left[\mathrm{Ca}^{2+}\right]_{\mathrm{e}}$ with less mitochondrial $\mathrm{Ca}^{2+}$ uptake and rapid $\mathrm{Ca}^{2+}$ release by the third or fourth $\mathrm{CaCl}_{2}$ pulse. The total $\mathrm{CRC}$ for the DMSO and OMN were comparable (i.e., $133.3 \pm 13.3 \mathrm{nmol} \mathrm{Ca}^{2+} / \mathrm{mg}$ protein and $146.6 \pm 13.3 \mathrm{nmol}$ $\mathrm{Ca}^{2+} / \mathrm{mg}$ protein, respectively) (Figure S1). In the presence of ADP, mitochondria took up more $\mathrm{Ca}^{2+}$ before pore opening and the CRC was further augmented with OMN+ADP; the CRC value increased from $213.3 \pm 13.3 \mathrm{nmol} \mathrm{Ca}{ }^{2+} / \mathrm{mg}$ protein for ADP alone to $373.3 \pm 35.3 \mathrm{nmol} \mathrm{Ca}{ }^{2+} / \mathrm{mg}$ protein for $\mathrm{OMN}+\mathrm{ADP}$ (Figure S1). Mitochondria treated with CsA before the addition of $\mathrm{CaCl}_{2}$ boluses displayed a more robust $\mathrm{Ca}^{2+}$ uptake, with a significantly higher $\mathrm{CRC}$ value, $573.3 \pm 26.6 \mathrm{nmol} \mathrm{Ca}{ }^{2+} / \mathrm{mg}$ protein, compared with all other groups (Figure 2A and Figure S1). Importantly, in CsA-treated mitochondria, the addition of $\mathrm{CaCl}_{2}$ pulses $(20 \mu \mathrm{M})$ did not significantly increase the ss[Ca $\left.\mathrm{Ca}^{2+}\right]_{e}$ until the sixth to seventh pulse (Figure $2 \mathrm{~B}$ ), suggesting enhanced $\mathrm{Ca}^{2+}$ uptake. Figure $2 \mathrm{C}$, summarizes the effects of the different treatments on the ss[Ca $\left.{ }^{2+}\right]_{\mathrm{e}}$ for cumulative additions of 80,140 , and $180 \mu \mathrm{M}$ of $\mathrm{Ca}^{2+}$, which corresponds to the fourth, seventh, and ninth $\mathrm{CaCl}_{2}$ pulses, respectively. The addition of $\mathrm{CsA}$ strongly blunted the $\mathrm{Ca}^{2+}$-induced increase in $\mathrm{ss}\left[\mathrm{Ca}^{2+}\right]_{e}$ by stimulating faster and more $\mathrm{Ca}^{2+}$ uptake. We observed that the $\mathrm{ss}\left[\mathrm{Ca}^{2+}\right]_{\mathrm{e}}$ was significantly lower for the CsA-treated mitochondria than for OMN+ADP-treated mitochondria after the cumulative addition of $\mathrm{CaCl}_{2}$ of $80 \mu \mathrm{M}(0.28 \pm 0.0 \mu \mathrm{M}$ vs. $0.50 \pm 0.02 \mu \mathrm{M}), 140 \mu \mathrm{M}(0.57 \pm 0.06 \mu \mathrm{M}$ vs. $0.77 \pm 0.06 \mu \mathrm{M})$, and $180 \mu \mathrm{M}(0.71 \pm 0.02 \mu \mathrm{M}$ vs. $0.95 \pm 0.1 \mu \mathrm{M}$ ) $\mathrm{CaCl}_{2}$, respectively (Figure $2 \mathrm{~B}, \mathrm{C}$ ). The sustained low ss $\left[\mathrm{Ca}^{2+}\right]_{\mathrm{e}}$ for an extended period of $\mathrm{CaCl}_{2}$ additions in the CsA-treated group indicates a maintained $\Delta \Psi_{\mathrm{m}}$ for $\mathrm{Ca}^{2+}$ uptake, resulting in enhanced $\mathrm{Ca}^{2+}$ loading capacity because of improved buffering.

We next examined $\left[\mathrm{Ca}^{2+}\right]_{e}$ dynamics in the situation in which mitochondrial matrix $\mathrm{Ca}^{2+}$ nearly reached threshold, as determined by the predicted opening of $\mathrm{MPTP}$; in this case we added CsA just before the anticipated mPTP opening. Using Protocol B (Figure 1), $\left[\mathrm{Ca}^{2+}\right]_{e}$ was measured and the kinetics were compared in response to adding either DMSO, ADP, OMN, OMN+ADP, or CsA just before the onset of the mPTP opening (Figure 2D). The dynamic changes in $\mathrm{ss}\left[\mathrm{Ca}^{2+}\right]_{\mathrm{e}}$ during the addition of different treatments are illustrated in more detail in the inset of Figure 2D. In the DMSO-treated mitochondria, three to four $\mathrm{Ca}^{2+}$ pulses (cumulative addition of $68 \pm 4.9 \mu \mathrm{M} \mathrm{CaCl}_{2}$ ) were sufficient to induce the release of matrix $\mathrm{Ca}^{2+}$. Addition of ADP or OMN reversed the initial pore opening and delayed matrix $\mathrm{Ca}^{2+}$ release by one to two pulses compared to DMSO. Addition of OMN+ADP also showed a significant reversal of $\mathrm{Ca}^{2+}$ release with reduction in the ss[Ca $\left.{ }^{2+}\right]_{\mathrm{e}}(0.74 \pm 0.18 \mu \mathrm{M})$. Thus, there was a considerable increase in the CRC by OMN+ADP compared to DMSO (Figure 2D and Figure S1) and a further delay in $\mathrm{mPTP}$ opening by one additional $\mathrm{CaCl}_{2}$ bolus compared to OMN or ADP alone. More impressively, the addition of CsA not only reversed the increasing trend of $\mathrm{ss}\left[\mathrm{Ca}^{2+}\right]_{\mathrm{e}}$ to the baseline levels $(0.42 \pm 0.06 \mu \mathrm{M})$ (Figure 2D,E), it further maintained the $\mathrm{ss}\left[\mathrm{Ca}^{2+}\right]_{e}$ at a constant low value for an additional twelve to thirteen $\mathrm{Ca}^{2+}$ pulses. This resulted in a four-fold and a two-fold increase in the CRC, compared to DMSO and $\mathrm{OMN}+\mathrm{ADP}$, respectively (Figure 2E,F and Figure S1).

Altogether, these results demonstrate that $\mathrm{CsA}$ enhances mitochondrial $\mathrm{Ca}^{2+}$ uptake, thereby inhibiting a consequent increase in free $\left[\mathrm{Ca}^{2+}\right]_{\mathrm{e}}$ during $\mathrm{CaCl}_{2}$ pulse challenges, leading to an increase in the CRC of the mitochondria. This sustained low ss $\left[\mathrm{Ca}^{2+}\right]_{\mathrm{e}}$ and concomitant increase in $\mathrm{Ca}^{2+}$ uptake are likely explained by enhanced $\left[\mathrm{Ca}^{2+}\right]_{\mathrm{m}}$ buffering to maintain basal $\left[\mathrm{Ca}^{2+}\right]_{\mathrm{m}}$, which results in a preserved $\Delta \Psi_{\mathrm{m}}$ for $\mathrm{Ca}^{2+}$ uptake and greater CRC. To investigate further the potential for $\mathrm{CsA}$ on mediating $\mathrm{Ca}^{2+}$ buffering, it was necessary to examine the effects of CsA on matrix $\left[\mathrm{Ca}^{2+}\right]_{\mathrm{m}}$ dynamics in the next set of experiments.

\subsection{Effect of $\mathrm{Cs} A$ on Matrix Free $\left[\mathrm{Ca}^{2+}\right]$ Handling}

Matrix $\mathrm{Ca}^{2+}$ was assessed with Fura-4 AM as described in Materials and Methods. We explored the effect of $\mathrm{CsA}$ on $\left[\mathrm{Ca}^{2+}\right]_{\mathrm{m}}$, under identical conditions and protocols as shown in Figure 1 (Protocols $\left.\mathrm{A}, \mathrm{B}\right)$. Mitochondrial $\mathrm{Ca}^{2+}$ buffering was measured as a function of a decrease in $\mathrm{Ca}^{2+}$ fluorescence, reaching 
a steady-state at approximately $270 \mathrm{~s}$ after each bolus of $\mathrm{CaCl}_{2}$ added. The magnitude of mitochondrial $\mathrm{Ca}^{2+}$ uptake for the first $\mathrm{CaCl}_{2}$ pulse $(20 \mu \mathrm{M})$ was similar in all groups; however, on subsequent additions of $\mathrm{CaCl}_{2}$, the ADP- and/or OMN-treated groups showed faster declines in $\left[\mathrm{Ca}^{2+}\right]_{\mathrm{m}}$ with lower mitochondrial steady-state $\left[\mathrm{Ca}^{2+}\right]_{\mathrm{m}}\left(\mathrm{ss}\left[\mathrm{Ca}^{2+}\right]_{\mathrm{m}}\right)$ and delayed $\mathrm{mPTP}$ opening compared to DMSO (Figure 3A,B). Interestingly, the CsA-treated group showed a small increase in $\mathrm{ss}\left[\mathrm{Ca}^{2+}\right]_{\mathrm{m}}$ with each $\mathrm{CaCl}_{2}$ pulse, but a gradual decline in ss $\left[\mathrm{Ca}^{2+}\right]_{\mathrm{m}}$ was observed after $\left[\mathrm{Ca}^{2+}\right]_{\mathrm{m}}$ exceeded $3 \pm 0.10 \mu \mathrm{M}$ with the cumulative addition of $100-150 \mu \mathrm{M} \mathrm{CaCl}_{2}$ (Figure 3A,B) and a significant increase in CRC up to fifteen to sixteen pulses. This suggested that the buffering effect of CsA on matrix $\mathrm{Ca}^{2+}$ is triggered when $\left[\mathrm{Ca}^{2+}\right]_{\mathrm{m}}$ reaches a certain value.

Protocol A: Pre-exposure

A

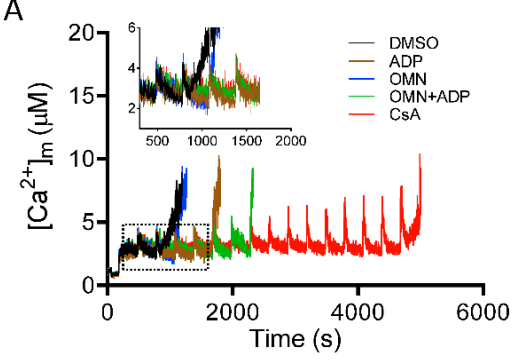

B

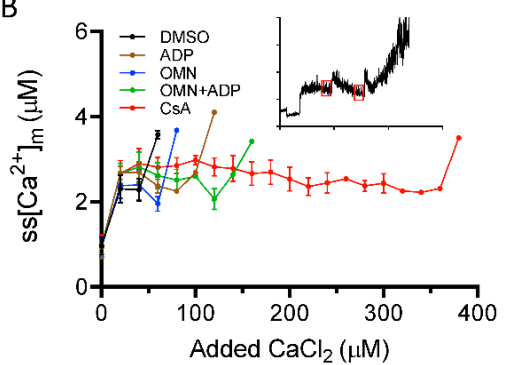

C

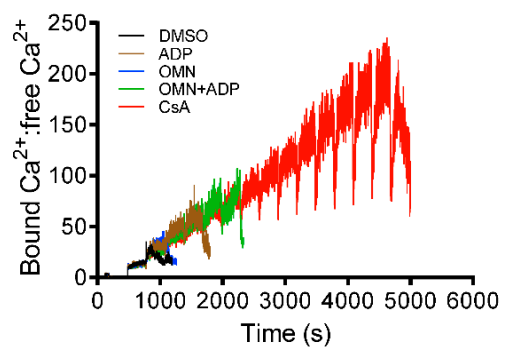

Protocol B: Rescue

D

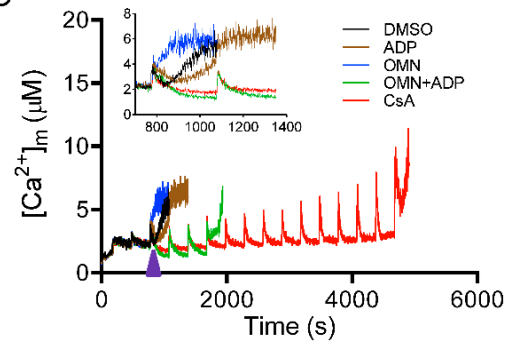

E

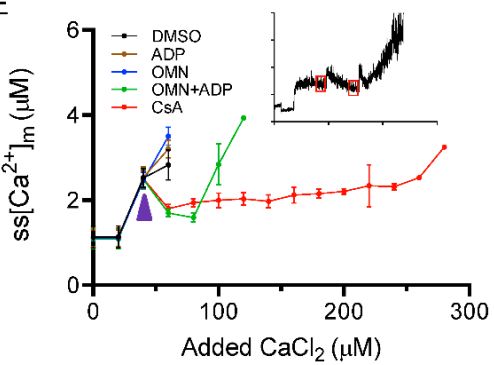

F

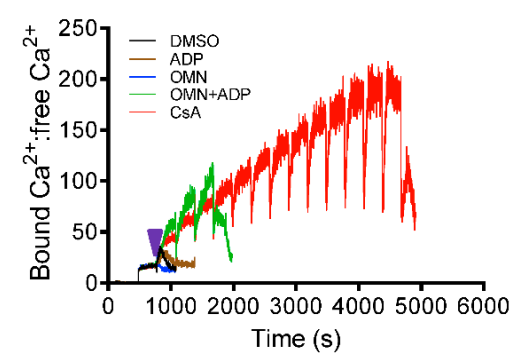

Figure 3. Effect of CsA and AdN on intra-matrix free $\mathrm{Ca}^{2+}\left(\left[\mathrm{Ca}^{2+}\right]_{m}\right)$ dynamics. Mitochondrial $\mathrm{Ca}^{2+}$ uptake and buffering for each treatment groups, DMSO (control; black trace), CsA (red trace), ADP (brown trace), oligomycin (OMN, blue trace), or combination of OMN+ADP (green trace) are shown using the protocols depicted in Figure 1. Mitochondrial suspension was exposed to $0.5 \mu \mathrm{M}$ CsA, $250 \mu \mathrm{M}$ ADP, $10 \mu \mathrm{M}$ OMN, or OMN+ADP before adding boluses of $20 \mu \mathrm{M} \mathrm{CaCl}_{2}$ (Protocol A; left column). Mitochondrial suspension was exposed to added boluses of $\mathrm{CaCl}_{2}(20 \mu \mathrm{M})$ and rescued from mPTP opening (Protocol B; right column) with similar interventions as in Protocol A, at a time point at which it would initiate mPTP opening. Representative traces show changes in $\left[\mathrm{Ca}^{2+}\right]_{m}$ over time in delay of mPTP opening (A) and rescue of mitochondria from mPTP opening (D). Insets (A,D) show $\mathrm{Ca}^{2+}$ uptake kinetics in detail. Steady-state $\left[\mathrm{Ca}^{2+}\right]_{\mathrm{m}}\left(\mathrm{ss}\left[\mathrm{Ca}^{2+}\right]_{\mathrm{m}}\right), 270 \mathrm{~s}$ after initiation of $\mathrm{Ca}^{2+}$ uptake, plotted as function of added $\mathrm{Ca}^{2+}(20 \mu \mathrm{M})$ every $300 \mathrm{~s}$ in delay of mPTP opening $(\mathbf{B})$ and rescue of mitochondria from mPTP from opening (E). Insets (B,E) indicate the time points at which ss[Ca $\left.{ }^{2+}\right]_{\mathrm{m}}$ was calculated. Change in matrix-bound $\mathrm{Ca}^{2+}$ :free $\mathrm{Ca}^{2+}$ over time in delay of mPTP opening $(\mathbf{C})$ and rescue of mitochondria from $\mathrm{mPTP}$ opening (F). Arrowhead indicates time of addition of DMSO, ADP, OMN, OMN+ADP, or CsA during Protocol B. 
To estimate the mitochondrial $\mathrm{Ca}^{2+}$ buffering capacity, the ratio of bound $\mathrm{Ca}^{2+}:$ free $\mathrm{Ca}^{2+}$ was calculated from the change in $\left[\mathrm{Ca}^{2+}\right]_{\mathrm{m}}$ (Figure 3A) to the total amount of $\mathrm{Ca}^{2+}$ taken up from the extra-matrix medium $\left(\Sigma \mathrm{Ca}^{2+}{ }_{\text {uptake }}\right):\left(\Sigma \mathrm{Ca}^{2+}{ }_{\text {uptake }}-\left[\mathrm{Ca}^{2+}\right]_{\mathrm{m}}\right) /\left[\mathrm{Ca}^{2+}\right]_{\mathrm{m}}$, as described previously [45]. Although the extent of bound $\mathrm{Ca}^{2+}$ :free $\mathrm{Ca}^{2+}$ at each $\mathrm{Ca}^{2+}$ pulse was comparable in all the treated groups (Figure 3C), the addition of CsA maintained the buffering capacity, with a gradual increase in the capacity to bind $\mathrm{Ca}^{2+}$ up to fifteen or sixteen $\mathrm{Ca}^{2+}$ pulses (Figure $3 \mathrm{C}$ ).

Greater uptake of $\mathrm{Ca}^{2+}$ from the extra-matrix space (indicated by lower ss $\left[\mathrm{Ca}^{2+}\right]_{\mathrm{e}}$ ), combined with lower ss $\left[\mathrm{Ca}^{2+}\right]_{\mathrm{m}}$, indicated a greater $\mathrm{Ca}^{2+}$ buffering capacity of mitochondria in the presence of CsA. Consistent with this notion, the calculated matrix $\mathrm{Ca}^{2+}$ buffering capacity $\left(\mathrm{m} \beta_{\mathrm{Ca}}\right)$ in CsA-treated mitochondria was about ten-fold higher compared to DMSO and two-fold higher than with OMN+ADP (Figure 4). This CsA-mediated increase in $\mathrm{m} \beta_{\mathrm{Ca}}$ is possibly due to an effect of CsA in triggering the matrix physiological buffers to enhance sequestration of $\mathrm{Ca}^{2+}$.

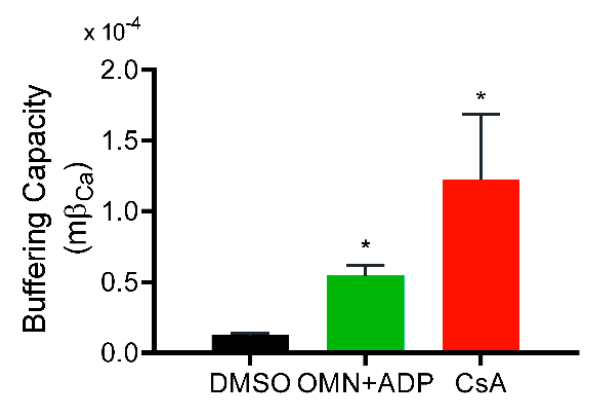

Figure 4. Effect of CsA and AdN on mitochondrial $\mathrm{Ca}^{2+}$ buffering capacity. Mitochondrial $\mathrm{Ca}^{2+}$ buffering capacity calculated from trend fits of $\left[\mathrm{Ca}^{2+}\right]_{\mathrm{e}}$ and $\left[\mathrm{Ca}^{2+}\right]_{\mathrm{m}}$ for DMSO-(control), CsA-, and OMN+ADP-treated mitochondria as described by Equations (2)-(4) in Materials and Methods. Buffering capacity for each treatment was calculated from three-five experiments each for $\left[\mathrm{Ca}^{2+}\right]_{\mathrm{e}}$ and $\left[\mathrm{Ca}^{2+}\right]_{\mathrm{m}}$ and averaged. Error bars represent mean $\pm \operatorname{SEM}\left({ }^{*} p<0.01\right.$ compared with DMSO).

After observing the high buffering capacity of mitochondria pre-treated with CsA before the $\mathrm{CaCl}_{2}$ bolus challenges, we next examined the effect of $\mathrm{CsA}$ on the rescue of mitochondria from $\mathrm{Ca}^{2+}$ release when the matrix $\mathrm{Ca}^{2+}$ buffering system (MCBS) becomes overwhelmed by the added boluses of $\mathrm{CaCl}_{2}$ (Figure 1B). As shown in Figure 3D,E, OMN and ADP, each failed to reverse the mitochondrial $\mathrm{Ca}^{2+}$ efflux with added boluses; however, adding CsA or OMN+ADP at similar time points significantly reduced ss $\left[\mathrm{Ca}^{2+}\right]_{\mathrm{m}}$ by reinstating $\mathrm{Ca}^{2+}$ sequestration. This reversal was more effective and sustained in the presence of CsA than with OMN+ADP. This observation is consistent with the calculated values of bound $\mathrm{Ca}^{2+}$ : free $\mathrm{Ca}^{2+}$, which increased two-fold for CsA compared to OMN+ADP (Figure 3F). Taken together, these data demonstrate that $\mathrm{CsA}$ increases the mitochondrial $\mathrm{Ca}^{2+}$ threshold for $\mathrm{mPTP}$ opening by activating $\left[\mathrm{Ca}^{2+}\right]_{\mathrm{m}}$ buffering that results in maintenance of a low ss $\left[\mathrm{Ca}^{2+}\right]_{\mathrm{m}}$.

\subsection{Effect of $\mathrm{Cs} A$ on $\mathrm{Ca}^{2+}$-Mediated Changes in $\triangle \Psi_{m}, \mathrm{NADH}$, and Matrix $p H$}

A major driving force for $\mathrm{Ca}^{2+}$ uptake, in addition to the chemical gradient, is a high IMM potential gradient $\left(\Delta \Psi_{\mathrm{m}}\right)$; but increased $\mathrm{Ca}^{2+}$ uptake without efflux or sequestration can decrease $\Delta \Psi_{\mathrm{m}}$ by flooding the matrix with positive charges. To strengthen the thesis that CsA increases the capacity of mitochondria to sequester $\mathrm{Ca}^{2+}$, we next investigated the effect of CsA on mitochondrial bioenergetics. $\Delta \Psi_{\mathrm{m}}, \mathrm{NADH}$, and $\mathrm{pH}_{\mathrm{m}}$ were assessed using the same protocols as described in Figure 1 for $\mathrm{CRC}$ to correlate changes in $\left[\mathrm{Ca}^{2+}\right]_{\mathrm{m}}$ to changes in bioenergetics over time. $\mathrm{mPTP}$ opening was marked by a sudden rise in the TMRM signal, indicating maximal depolarization of $\Psi_{\mathrm{m}}$. Correspondingly, the oxidation of NADH was marked by a decrease in matrix NADH signal intensity when mPTP opens. Figure 5 shows representative traces of $\Delta \Psi_{\mathrm{m}}, \mathrm{NADH}$, and $\mathrm{pH}_{\mathrm{m}}$ for each experimental condition. The rate of $\Delta \Psi_{\mathrm{m}}$ depolarization and NADH oxidation correlated well with the induction of MPTP, as seen in the CRC data. The loss of CRC coincided with total $\Delta \Psi_{\mathrm{m}}$ 
dissipation and NADH oxidation. DMSO-treated mitochondria (control) exhibited rapid $\mathrm{Ca}^{2+}$-induced $\Delta \Psi_{\mathrm{m}}$ depolarization and $\mathrm{NADH}$ oxidation (black trace) after only a few $\mathrm{CaCl}_{2}$ pulses. Addition of $\mathrm{OMN}+\mathrm{ADP}$ significantly delayed the $\mathrm{Ca}^{2+}$ induced $\Delta \Psi_{\mathrm{m}}$ depolarization and NADH oxidation when compared to DMSO, with $533.3 \pm 26.7 \mathrm{nmol} \mathrm{Ca}{ }^{2+} / \mathrm{mg}$ protein vs. $200 \pm 23 \mathrm{nmol} \mathrm{Ca}{ }^{2+} / \mathrm{mg}$ protein and $546.7 \pm 18.9 \mathrm{nmol} \mathrm{Ca}{ }^{2+} / \mathrm{mg}$ protein vs. $173.3 \pm 13.3 \mathrm{nmol} \mathrm{Ca}^{2+} / \mathrm{mg}$ protein $\mathrm{Ca}^{2+}$ capacity, respectively (Figure 5A,B). Mitochondria treated with CsA maintained $\Delta \Psi_{\mathrm{m}}$ and NADH for a higher number of $\mathrm{CaCl}_{2}$ pulses than with OMN+ADP $\left(666.7 \pm 13.3 \mathrm{nmol} \mathrm{Ca}^{2+} / \mathrm{mg}\right.$ protein, and $626.6 \pm 13.3 \mathrm{nmol}$ $\mathrm{Ca}^{2+} / \mathrm{mg}$ protein, respectively) (Figure $\left.5 \mathrm{~A}, \mathrm{~B}\right)$. Mitochondrial matrix $\mathrm{pH}\left(\mathrm{pH}_{\mathrm{m}}\right)$ is known to modulate mitochondrial $\mathrm{P}_{\mathrm{i}}$ concentration and thus influence the matrix $\mathrm{Ca}^{2+}$ buffering [14]. The presence of $\mathrm{CsA}$ maintained $\mathrm{pH}_{\mathrm{m}}$ at a basal level until $\mathrm{mPTP}$ opened (Figure 5C).

Protocol A: Pre-exposure

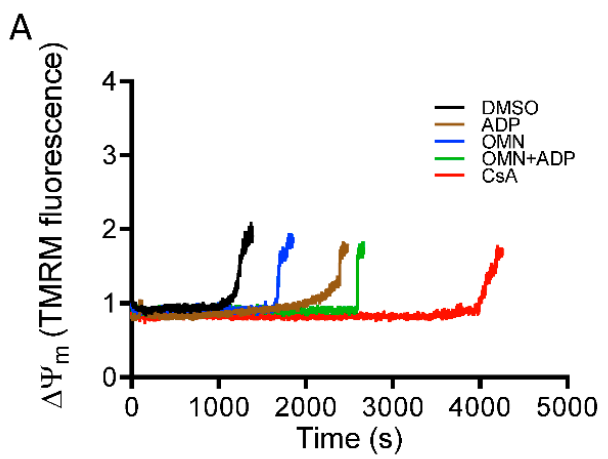

B

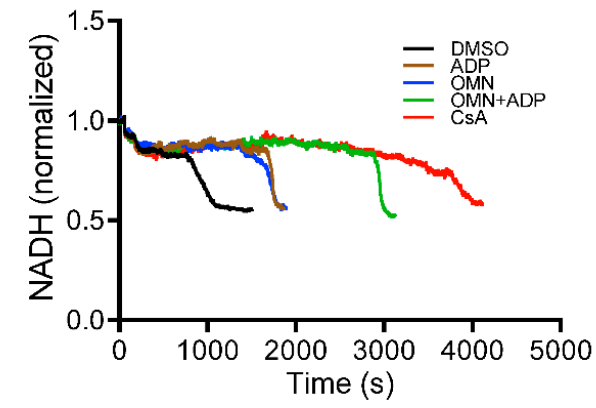

C

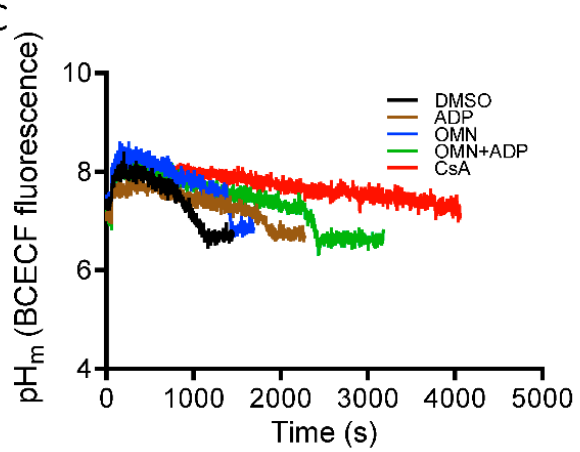

Protocol B: Rescue

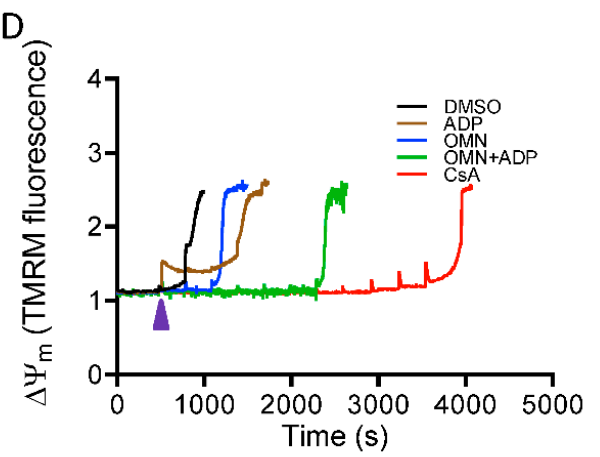

E
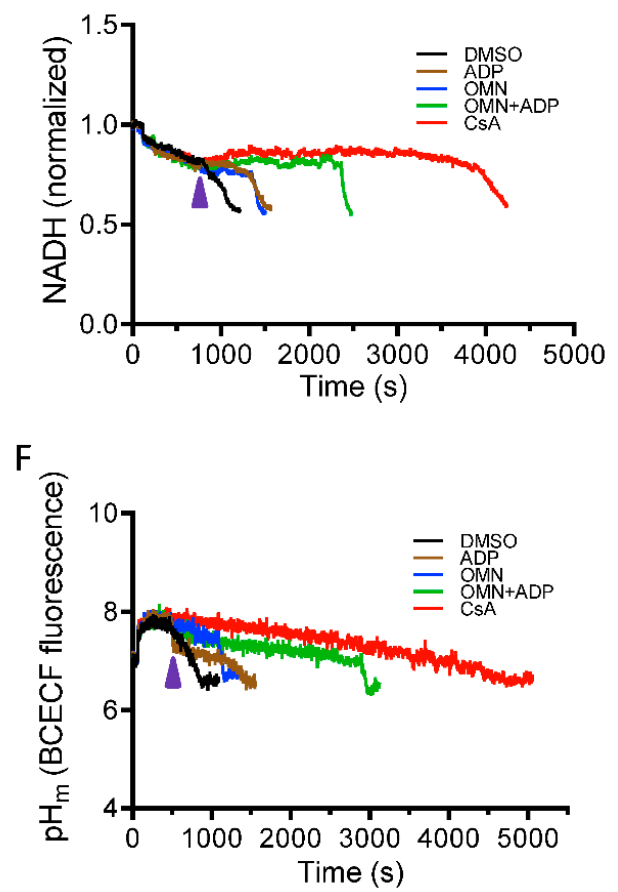

Figure 5. Effect of $\mathrm{CsA}$ and $\mathrm{AdN}$ on mitochondrial bioenergetics. The bioenergetic responses during Protocols A (left column) and B (right column) were monitored using the $\Delta \Psi_{\mathrm{m}}$ sensitive dye TMRM (tetramethylrhodamine methyl ester perchlorate) (A,D), NADH autofluorescence (B,E), and $\mathrm{pH}_{\mathrm{m}}$-sensitive dye BCECF ${ }^{\mathrm{AM}}$ (2',7'-Bis-(2-Carboxyethyl)-5-(and-6)-carboxyfluorescein, acetoxymethyl ester AM) (C,F). Purple arrowhead indicates time of addition of DMSO $(1 \mu \mathrm{M})$, ADP $(250 \mu \mathrm{M})$, OMN $(10 \mu \mathrm{M}), \mathrm{OMN}+\mathrm{ADP}$, or CsA $(0.5 \mu \mathrm{M})$ during Protocol B. 
In Protocol B, intervention with OMN + ADP or CsA maintained $\Delta \Psi_{\mathrm{m}}$, mitochondrial NADH, and $\mathrm{pH}_{\mathrm{m}}$ (Figure 5D-F), and contributed to the improved capacity of mitochondria to take up and sequester additional $\mathrm{Ca}^{2+}$ after $\mathrm{CaCl}_{2}$ pulses. However, OMN+ADP was less effective in preserving $\Delta \Psi_{\mathrm{m}}, \mathrm{NADH}$, and $\mathrm{pH}_{\mathrm{m}}$ compared to CsA. This incapacity to sustain the bioenergetic status in the $\mathrm{OMN}+\mathrm{ADP}-\mathrm{vs}$. CsA-treated mitochondria during $\mathrm{CaCl}_{2}$ challenges reflects a lower capacity to sequester $\mathrm{Ca}^{2+}$ in the matrix for a protracted time.

In summary, maintenance of $\Delta \Psi_{\mathrm{m}}, \mathrm{NADH}$, and $\mathrm{pH}_{\mathrm{m}}$ in the presence of CsA is consistent with changes in $\left[\mathrm{Ca}^{2+}\right]_{e}$ and $\left[\mathrm{Ca}^{2+}\right]_{\mathrm{m}}$ that reflect greater $\mathrm{Ca}^{2+}$ sequestration (Figure S2) and uptake. Collectively, these results indicate that CsA reduced the accumulation of $\left[\mathrm{Ca}^{2+}\right]_{\mathrm{m}}$, by potentiating matrix $\mathrm{Ca}^{2+}$ buffering, which in turn, maintained $\Delta \Psi_{\mathrm{m}}, \mathrm{NADH}$, and $\mathrm{pH}_{\mathrm{m}}$ necessary for normal mitochondrial function. Together, these mitochondrial variables preserve mitochondria and protect against $\mathrm{mPTP}$ opening.

\subsection{Time Dependent Effect of CsA Addition on Rescue of Mitochondria from Imminent $\mathrm{Ca}^{2+}$-Induced mPTP Opening}

After demonstrating that CsA can reverse the induction of mPTP opening (Figures 2, 3 and 5), we next investigated the dynamics of $\left[\mathrm{Ca}^{2+}\right]_{\mathrm{e}},\left[\mathrm{Ca}^{2+}\right]_{\mathrm{m}}$ and $\Delta \Psi_{\mathrm{m}}$, by adding CsA at three different time points, before the onset of MPTP opening. This approach allowed us to determine the threshold at which CsA can effectively restore the mitochondrial sequestration system that will protect mitochondria from $\mathrm{Ca}^{2+}$ overload-mediated pore opening. Figure 6 , panels A-C, show changes in $\left[\mathrm{Ca}^{2+}\right]_{\mathrm{e}},\left[\mathrm{Ca}^{2+}\right]_{\mathrm{m}}$, and $\Delta \Psi_{\mathrm{m}}$ depolarization, induced by adding $\mathrm{CsA}$ at 1,2 , and $3 \mathrm{~min}$ after the last $\mathrm{CaCl}_{2}$ bolus in which mitochondrial $\mathrm{Ca}^{2+}$ uptake was observed before pore opened. Right panels D-F show detailed (close up) comparison of kinetics of $\left[\mathrm{Ca}^{2+}\right]_{\mathrm{e}},\left[\mathrm{Ca}^{2+}\right]_{\mathrm{m}}$, and $\Delta \Psi_{\mathrm{m}}$ after adding $\mathrm{CsA}$ at different time points. Adding CsA at all three tested time points, markedly delayed the large increase in $\left[\mathrm{Ca}^{2+}\right]_{\mathrm{e}}$ due to mitochondrial $\mathrm{Ca}^{2+}$ release. However, the effect of CsA to prolong $\mathrm{Ca}^{2+}$ uptake, which eventually maintains ss $\left[\mathrm{Ca}^{2+}\right]_{\mathrm{e}}$ at baseline, diminished as the interval before $\mathrm{CsA}$ addition and $\left[\mathrm{Ca}^{2+}\right]_{\mathrm{e}}$ accumulation was lengthened (Figure $6 \mathrm{~A}$ ). Adding CsA at 1 min caused a decline in $\left[\mathrm{Ca}^{2+}\right]_{\mathrm{e}}$, with a marked decrease in ss $\left[\mathrm{Ca}^{2+}\right]_{\mathrm{e}}$ $(0.39 \pm 0.07 \mu \mathrm{M})$ of the succeeding $\mathrm{Ca}^{2+}$ pulses, compared to adding CsA at $2 \mathrm{~min}(0.67 \pm 0.03 \mu \mathrm{M})$ and $3 \mathrm{~min}(0.84 \pm 0.05 \mu \mathrm{M})$ (Figure $6 \mathrm{D}$; inset). In addition, we examined for changes in kinetics of $\left[\mathrm{Ca}^{2+}\right]_{\mathrm{m}}$ with $\mathrm{CsA}$ added at the same time points (Figure $6 \mathrm{~B}$ ). The rate of maximal $\mathrm{Ca}^{2+}$ buffering (i.e., the time to reach steady-state $\left[\mathrm{Ca}^{2+}\right]_{\mathrm{m}}$ ) and the $\mathrm{Ca}^{2+}$ threshold for pore opening was significantly higher when CsA was added at the early time points (i.e., 1 and $2 \mathrm{~min}$ ) compared to the late time point of $3 \mathrm{~min}$ (Figure 6E, inset).

Next, in a parallel study, we monitored the corresponding changes in $\Delta \Psi_{\mathrm{m}}$ profile at the same rescue time points $(1,2$, or $3 \mathrm{~min})$. Adding $\mathrm{CsA}$ reversed the $\mathrm{Ca}^{2+}$-induced $\Delta \Psi_{\mathrm{m}}$ depolarization even after a large depolarization (i.e., at $3 \mathrm{~min}$; Figure $6 \mathrm{C}, \mathrm{F}$ ). Similar to its effect on $\left[\mathrm{Ca}^{2+}\right]_{\mathrm{e}}$ and $\left[\mathrm{Ca}^{2+}\right]_{\mathrm{m}}$, CsA restored and maintained $\Delta \Psi_{\mathrm{m}}$ for a longer period at rescue points of $1 \mathrm{~min}$ vs. 2 and $3 \mathrm{~min}$. Thus, at these points of intervention, CsA suppressed mPTP opening by increasing matrix $\mathrm{Ca}^{2+}$ buffering capacity, which maintained $\Delta \Psi_{\mathrm{m}}$ and the driving force for further $\mathrm{Ca}^{2+}$ uptake (Figure $6 \mathrm{C}$ ). Together, these results demonstrate that the magnitude of CsA-mediated increase in $\mathrm{Ca}^{2+}$ threshold for mPTP opening and maintenance of mitochondrial integrity is dependent on the $\left[\mathrm{Ca}^{2+}\right]_{\mathrm{m}}$ level before CsA intervention. 
A

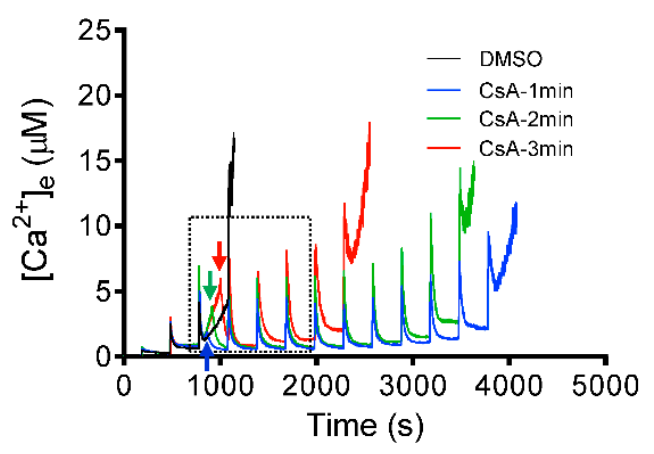

B

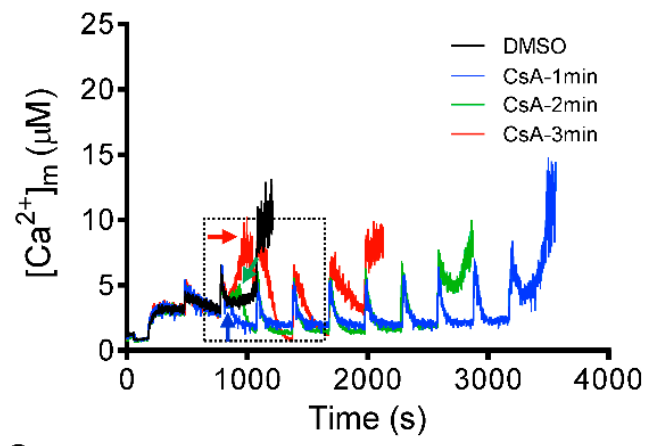

C

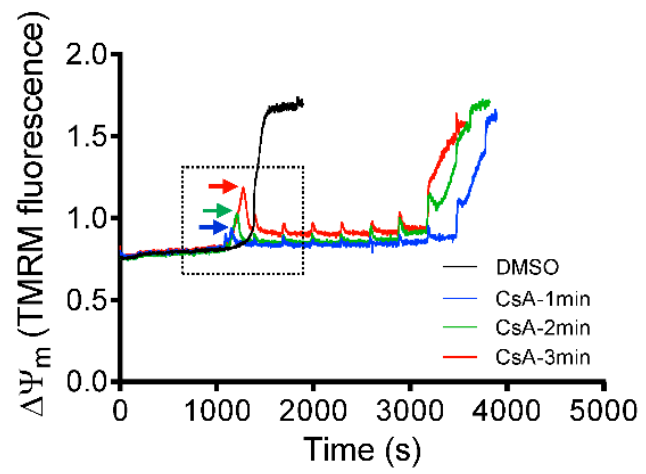

D

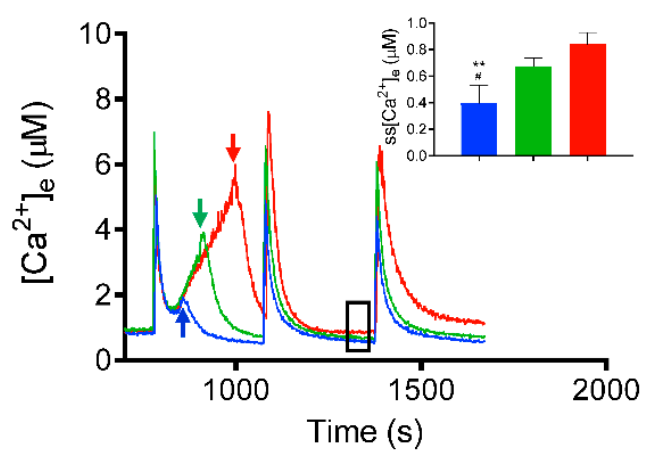

$\mathrm{E}$

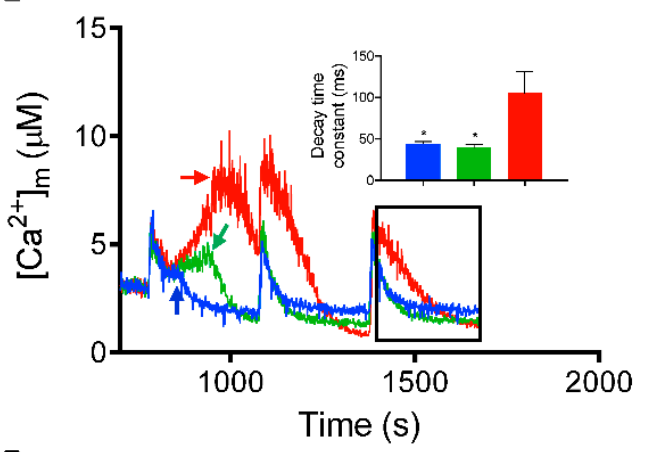

$\mathrm{F}$

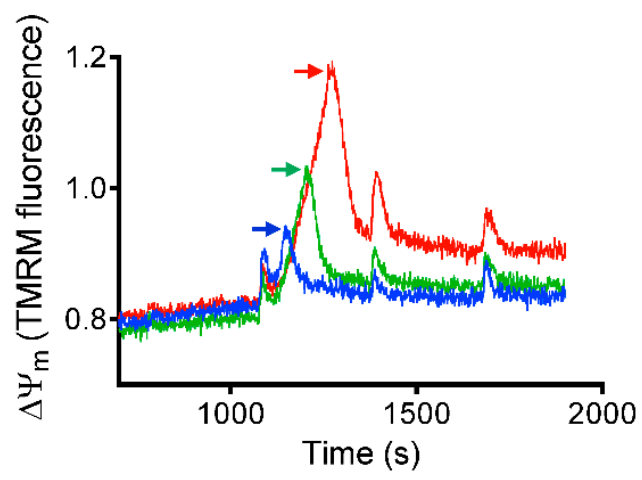

Figure 6. Time-dependent effects of $\mathrm{CsA}$ on mitochondrial $\mathrm{Ca}^{2+}$ dynamics and bioenergetics during rescue of mitochondria from mPTP opening. Changes in (A) extra-matrix free $\mathrm{Ca}^{2+}\left(\left[\mathrm{Ca}^{2+}\right]_{\mathrm{e}}\right)$, (B) intra-matrix free $\mathrm{Ca}^{2+}\left(\left[\mathrm{Ca}^{2+}\right]_{\mathrm{m}}\right)$ and $(\mathrm{C}) \Delta \Psi_{\mathrm{m}}$, when CsA was added at $1 \mathrm{~min}$ (blue trace), $2 \mathrm{~min}$ (green trace), and $3 \mathrm{~min}$ (red trace) after the last $\mathrm{Ca}^{2+}$ bolus before another $\mathrm{Ca}^{2+}$ bolus would have caused mPTP opening. Right panels show the effect of CsA on (D) $\left[\mathrm{Ca}^{2+}\right]_{\mathrm{e}},(\mathbf{E})\left[\mathrm{Ca}^{2+}\right]_{\mathrm{m}}$, and (F) $\Delta \Psi_{\mathrm{m}}$ dynamics during rescue of mitochondria from $\mathrm{mPTP}$ opening in greater detail. Insets $(\mathbf{D}, \mathbf{E})$ show relative ss $\left[\mathrm{Ca}^{2+}\right]_{\mathrm{e}}$ and decay time constant (ms) at specified time points (black dotted box), respectively. Arrows indicate time of addition of CsA $(0.5 \mu \mathrm{M})$. Error bars represent mean \pm SEM ( ${ }^{*} p<0.05,{ }^{* *} p<0.01$ vs. 3 min and ${ }^{\#} p<0.05$ vs. 2 min).

\subsection{Role of Inorganic Phosphate in CsA-Induced $\left[\mathrm{Ca}^{2+}\right]_{m}$ Regulation.}

Inorganic phosphate $\left(\mathrm{P}_{\mathrm{i}}\right)$ is a required component for mitochondrial matrix $\mathrm{Ca}^{2+}$ buffering $[14,29]$. To gain insight into the mechanism that underlies CsA-mediated activation of the MCBS, we monitored mitochondrial $\mathrm{Ca}^{2+}$ handling and $\Delta \Psi_{\mathrm{m}}$ during repeated boluses of $20 \mu \mathrm{M} \mathrm{CaCl}_{2}$ every $5 \mathrm{~min}$, as described in Materials and Methods, but now in the absence of $P_{i}$. With mitochondria depleted of $\mathrm{P}_{\mathrm{i}}$, and in $\mathrm{P}_{\mathrm{i}}$-free media, the CRC of mitochondria treated with CsA before the $\mathrm{CaCl}_{2}$ pulses was not different from DMSO (control). In addition, these mitochondria showed a gradual increase in $\mathrm{ss}\left[\mathrm{Ca}^{2+}\right]_{\mathrm{e}}$ and interestingly, after cumulative additions of $\mathrm{CaCl}_{2}$ to $80 \pm 15 \mu \mathrm{M}$, there was a significant 
decrease in mitochondrial $\mathrm{Ca}^{2+}$ uptake during additional $\mathrm{CaCl}_{2}$ pulses (Figure 7A). These results implicated a $\mathrm{P}_{\mathrm{i}}$-dependent mechanism in the CsA-mediated delay in mPTP opening. In contrast, ADP and OMN+ADP, but not OMN alone, caused a significant delay in MPTP opening (Figure 7A) in the absence of $P_{i}$.

A

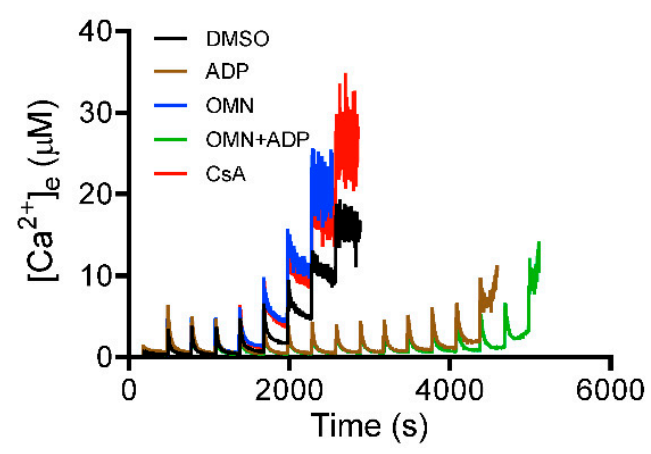

C

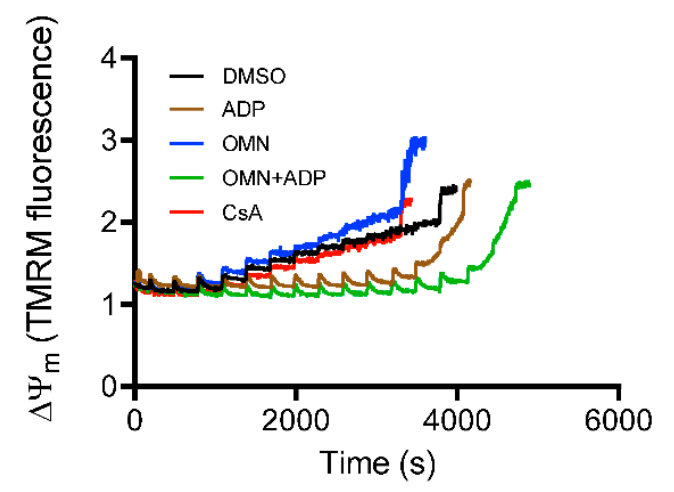

B

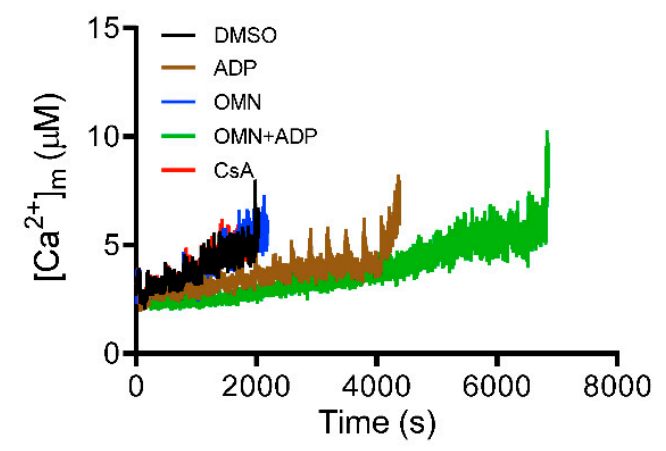

D

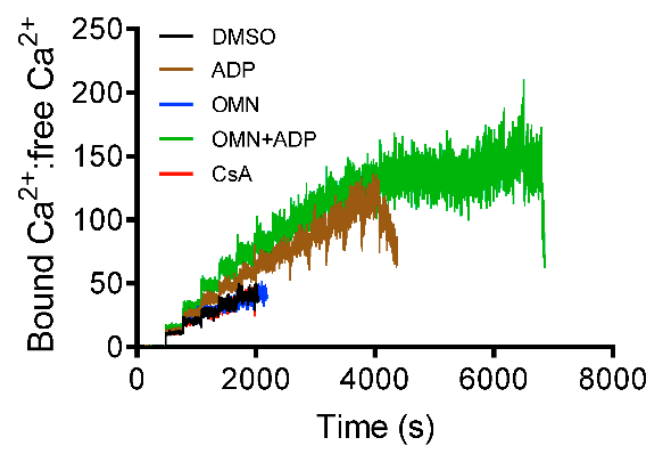

Figure 7. Effect of $\mathrm{P}_{\mathrm{i}}$ on CsA-induced mitochondrial $\mathrm{Ca}^{2+}$ handling and bioenergetics. Time course of $\left[\mathrm{Ca}^{2+}\right]_{\mathrm{e}}(\mathbf{A}),\left[\mathrm{Ca}^{2+}\right]_{\mathrm{m}}(\mathbf{B}), \Delta \Psi_{\mathrm{m}}(\mathbf{C})$, and matrix-bound $\mathrm{Ca}^{2+}$ :free $\mathrm{Ca}^{2+}(\mathbf{D})$ during consecutive additions of $20 \mu \mathrm{M} \mathrm{CaCl}_{2}$ to a suspension of $\mathrm{P}_{\mathrm{i}}$-depleted mitochondria, pre-exposed to DMSO (control), CsA, ADP, OMN, or OMN+ADP.

Along with observing the $\mathrm{P}_{\mathrm{i}}$-mediated effect of $\mathrm{CsA}$ on $\left[\mathrm{Ca}^{2+}\right]_{\mathrm{e}}$ dynamics, we also measured $\left[\mathrm{Ca}^{2+}\right]_{\mathrm{m}}$ under identical conditions. In the absence of $\mathrm{P}_{\mathrm{i}}$, mitochondria showed a gradual increase in $\mathrm{ss}\left[\mathrm{Ca}^{2+}\right]_{\mathrm{m}}$; matrix $\mathrm{Ca}^{2+}$ sequestration was strongly blunted in both DMSO-and CsA-treated groups. This reflected diminished buffering capacity with the increase in $\left[\mathrm{Ca}^{2+}\right]_{\mathrm{m}}$ (Figure 7B). However, in the presence of ADP and OMN+ADP in the $\mathrm{P}_{\mathrm{i}}$-depleted condition, mitochondria displayed robust CRC and enhanced $\mathrm{Ca}^{2+}$ buffering and thus decreased $\left[\mathrm{Ca}^{2+}\right]_{\mathrm{m}}$ (Figure 7B). Intriguingly, this effect was stronger than in the $\mathrm{P}_{\mathrm{i}}$ replete condition (Figure 3). Mitochondria also showed an increased ratio of bound $\mathrm{Ca}^{2+}$ :free $\mathrm{Ca}^{2+}$ in the OMN+ADP-treated group, but not in the DMSO and CsA groups (Figure 7D). These data further support the premise that $\mathrm{P}_{\mathrm{i}}$ is crucial in CsA-induced matrix $\mathrm{Ca}^{2+}$ buffering and $\mathrm{P}_{\mathrm{i}}$ is a requisite component of matrix calcium sequestration.

Since we observed significant attenuation of $\mathrm{Ca}^{2+}$ uptake and buffering by CsA in the absence of $\mathrm{P}_{\mathrm{i}}$, we addressed how the altered mitochondrial $\mathrm{Ca}^{2+}$ dynamics impacted $\Delta \Psi_{\mathrm{m}}$. Analysis of $\Delta \Psi_{\mathrm{m}}$ in mitochondria depleted of $\mathrm{P}_{\mathrm{i}}$ during $\mathrm{CaCl}_{2}$ bolus challenges revealed a gradual depolarization with each $\mathrm{Ca}^{2+}$ pulse over time in the DMSO-, OMN-, and CsA-treated groups (Figure 7C); this was consistent with the low $\mathrm{CRC}$ in these three groups due to the poor buffering after additional $\mathrm{CaCl}_{2}$ pulses. In contrast, mitochondria exposed to ADP or OMN+ADP in the $\mathrm{P}_{\mathrm{i}}$-depleted state exhibited restored and sustained $\Delta \Psi_{\mathrm{m}}$, which supported a robust CRC (Figure 7C). 
To further confirm the requisite role of $\mathrm{P}_{\mathrm{i}}$ in mediating CsA-induced activation of the MCBS, a rescue experiment with $5 \mathrm{mM} \mathrm{P}_{\mathrm{i}}$ was performed with DMSO-and CsA-treated groups in $\mathrm{P}_{\mathrm{i}}$-depleted condition. With addition of deionized $\mathrm{H}_{2} \mathrm{O}$ (vehicle), pore opening was not prevented in either group (data not shown). The addition of exogenous $\mathrm{P}_{\mathrm{i}}$ to the buffer triggered a rapid reversal of $\mathrm{Ca}^{2+}$ release (decrease in $\left(\left[\mathrm{Ca}^{2+}\right]_{\mathrm{e}}\right)$ in parallel with complete restoration of $\Delta \Psi_{\mathrm{m}}$ (Figure 8). In contrast, additional $\mathrm{Ca}^{2+}$ pulses in the $P_{\mathrm{i}}$ free DMSO-treated group failed to maintain ss $\left[\mathrm{Ca}^{2+}\right]_{e}$ and basal $\Psi_{\mathrm{m}}$, and induced rapid $\mathrm{Ca}^{2+}$ efflux (Figure 8). However, the CsA-treated mitochondria showed a robust uptake of $\left[\mathrm{Ca}^{2+}\right]_{\mathrm{e}}$ with low ss $\left[\mathrm{Ca}^{2+}\right]_{e}$ and sustained $\Delta \Psi_{\mathrm{m}}$ maintenance with additional $\mathrm{CaCl}_{2}$ boluses (Figure 8). Taken together, these results establish that $\mathrm{P}_{\mathrm{i}}$ is required for CsA-mediated mitochondrial $\mathrm{Ca}^{2+}$ buffering that maintains low $\left[\mathrm{Ca}^{2+}\right]_{m}$ and preserves $\Delta \Psi_{m}$; this in turn contributes to the capacity for more $\mathrm{Ca}^{2+}$ uptake and thus increases the $\mathrm{Ca}^{2+}$ threshold for mPTP opening.

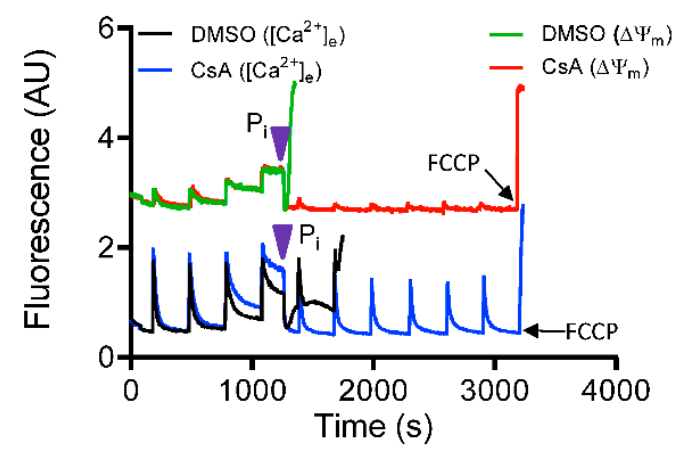

Figure 8. Mitochondrial $\mathrm{Ca}^{2+}$ modulation by $\mathrm{CsA}$ is phosphate $\left(\mathrm{P}_{\mathrm{i}}\right)$-dependent. Representative traces show change in extra-matrix $\mathrm{Ca}^{2+}$ fluorescence (Fura-4F Ratio) and $\Delta \Psi_{\mathrm{m}}$ during consecutive $20 \mu \mathrm{M}$ $\mathrm{CaCl}_{2}$ boluses to induce mPTP opening in $\mathrm{P}_{\mathrm{i}}$-depleted mitochondria. $\mathrm{P}_{\mathrm{i}}$ was added (purple arrowhead) at threshold point when mitochondria exhibited limited uptake of $\mathrm{Ca}^{2+}$ from the buffer.

\section{Discussion}

Matrix free $\left[\mathrm{Ca}^{2+}\right]\left(\left[\mathrm{Ca}^{2+}\right]_{\mathrm{m}}\right)$ plays two important roles: (i) Activation of $\mathrm{Ca}^{2+}$-dependent dehydrogenases for oxidative phosphorylation at low concentrations [46]; and (ii) regulation of cytosolic $\mathrm{Ca}^{2+}$ by sequestration of excess $\mathrm{Ca}^{2+}$ at high concentrations [47]. Excessive accumulation of free $\left[\mathrm{Ca}^{2+}\right]_{\mathrm{m}}$ is a leading factor in inducing mPTP opening. It is well established that repetitive mitochondrial $\mathrm{Ca}^{2+}$ loading triggers a gradual increase in $\left[\mathrm{Ca}^{2+}\right]_{\mathrm{m}}$, leading to a loss of IMM integrity that results in dissipation of $\Delta \Psi_{\mathrm{m}}$ and release of $\mathrm{Ca}^{2+}$. CsA is known to delay pore opening, in part, by inhibiting the PPIase activity of Cyp-D [31]. Whether CsA-mediated delay in mPTP opening involves regulation of $\left[\mathrm{Ca}^{2+}\right]_{m}$ by $\mathrm{P}_{\mathrm{i}}$-induced matrix $\mathrm{Ca}^{2+}$ buffering has not been addressed before. In this study, we investigated the effects of $\mathrm{CsA}$ on $\left[\mathrm{Ca}^{2+}\right]_{\mathrm{m}}$ regulation during repeated $\mathrm{Ca}^{2+}$ loading and its functional significance in MPTP opening. Additionally, we determined if changes in $\left[\mathrm{Ca}^{2+}\right]_{m}$ induced by CsA correlated with changes in mitochondrial bioenergetics under identical experimental conditions and if matrix $P_{i}$ was required for the observed CsA effects.

Since the key postulate was that $\mathrm{CsA}$ contributes to mitochondrial $\mathrm{Ca}^{2+}$ buffering, all experiments were performed in $\mathrm{Na}^{+}$-free condition to completely block NCLX as a route for efflux of excess matrix $\mathrm{Ca}^{2+}$. This allowed us to directly assess mitochondrial $\mathrm{Ca}^{2+}$ buffering capacity under different treatments. Our major findings during repetitive $\mathrm{CaCl}_{2}$ bolus challenges are: (i) CsA maintained basal ss $\left[\mathrm{Ca}^{2+}\right]_{\mathrm{m}}$ owing to increased mitochondrial $\mathrm{Ca}^{2+}$ buffering capacity; (ii) the effectiveness of CsA to maintain basal ss $\left[\mathrm{Ca}^{2+}\right]_{\mathrm{m}}$ correlates well with preserved mitochondrial bioenergetics; (iii) the buffering effect of CsA in a $\mathrm{P}_{\mathrm{i}}$-replete buffer was more pronounced than the known buffering effect of OMN+ADP; (iv) CsA-induced buffering was abolished in $\mathrm{P}_{\mathrm{i}}$-depleted mitochondria and $\mathrm{P}_{\mathrm{i}}$-free experimental medium. We conclude that the CsA-mediated delay in mPTP opening could, in large part, be attributed to CsA-induced activation of a $\mathrm{P}_{\mathrm{i}}$-dependent mitochondrial $\mathrm{Ca}^{2+}$ buffering system (MCBS), which maintains a low free $\left[\mathrm{Ca}^{2+}\right]_{\mathrm{m}}$ and preserves mitochondrial bioenergetics. 


\subsection{CsA-Mediated Inhibition of mPTP Opening Relates to the $s s\left[\mathrm{Ca}^{2+}\right]_{m}$}

Using the two protocols (Figure $1 \mathrm{~A}, \mathrm{~B}$ ), we examined the changes in $\left[\mathrm{Ca}^{2+}\right]_{\mathrm{e}}$ and $\left[\mathrm{Ca}^{2+}\right]_{\mathrm{m}}$ in response to boluses of $\mathrm{CaCl}_{2}$ in the presence of vehicle (DMSO), CsA, ADP, OMN, or OMN+ADP over time. Our experimental approaches allowed us to define the contribution of CsA in the regulation of $\left[\mathrm{Ca}^{2+}\right]_{\mathrm{m}}$ when CsA was given before the $\mathrm{CaCl}_{2}$ boluses (Protocol A) and at the threshold for pore opening under condition of increased free $\left[\mathrm{Ca}^{2+}\right]_{\mathrm{m}}$ accumulation (Protocol B). Our results clearly indicate that the effect of CsA on delaying $\mathrm{MPTP}$ opening is due largely to its efficacy in maintaining free $\mathrm{ss}\left[\mathrm{Ca}^{2+}\right]_{\mathrm{m}}$ by activating the MCBS in a $\mathrm{P}_{\mathrm{i}}$-dependent manner, and thereby preclude early mitochondrial $\mathrm{Ca}^{2+}$ overload and delay induction of mPTP opening. Sustained low ss $\left[\mathrm{Ca}^{2+}\right]_{\mathrm{e}}$ in the CsA-treated group indicated increasing mitochondrial $\mathrm{Ca}^{2+}$ uptake driven by the enhanced sequestration of free $\left[\mathrm{Ca}^{2+}\right]_{\mathrm{m}}$ to maintain a transmembrane $\mathrm{Ca}^{2+}$ gradient and a charged $\Delta \Psi_{\mathrm{m}}$ that facilitated additional $\mathrm{Ca}^{2+}$ uptake (Figure 2). Unlike previous studies [14,33,34], NCLX was blocked under our experimental conditions, to prevent $\mathrm{Ca}^{2+}$ efflux during the repetitive $\mathrm{CaCl}_{2}$ additions; therefore, the net free ss[Ca$\left.{ }^{2+}\right]_{\mathrm{m}}$ in our study was determined by the balance between $\mathrm{Ca}^{2+}$ uptake and $\mathrm{Ca}^{2+}$ sequestration.

Notably, the CsA-induced buffering of mitochondrial $\mathrm{Ca}^{2+}$ resulted in greater $\mathrm{Ca}^{2+}$ uptake to attain a steady-state, as shown by the gradual decrease in ss $\left[\mathrm{Ca}^{2+}\right]_{\mathrm{m}}$ with each added $\mathrm{CaCl}_{2}$ pulse (Figure 3). Insofar as $\mathrm{Ca}^{2+}-\mathrm{P}_{\mathrm{i}}$ precipitation is a major mechanism for mitochondrial $\mathrm{Ca}^{2+}$ buffering, the sustained $\mathrm{ss}\left[\mathrm{Ca}^{2+}\right]_{\mathrm{m}}$ after each $\mathrm{CaCl}_{2}$ bolus indicated matrix $\mathrm{Ca}^{2+}$ storage, likely in the form of various inorganic Ca-P $\mathrm{P}_{\mathrm{i}}$ complexes [14]. The low and maintained $\mathrm{ss}\left[\mathrm{Ca}^{2+}\right]_{\mathrm{m}}$ during continuous matrix $\mathrm{Ca}^{2+}$ uptake is consistent with formation of these complexes. Although our study did not provide direct experimental evidence for $\mathrm{CsA}$-induced matrix $\mathrm{Ca}-\mathrm{P}_{\mathrm{i}}$ complex formation, the continuous rise in estimated bound $\mathrm{Ca}^{2+}$ :free $\mathrm{Ca}^{2+}$ ratio with each $\mathrm{CaCl}_{2}$ bolus as well as the ten-fold increase in $\mathrm{m} \beta_{\mathrm{Ca}}$ clearly reflects a CsA effect on $\left[\mathrm{Ca}^{2+}\right]_{\mathrm{m}}$ buffering capacity (Figure 3 ).

The protective effect of CsA in delaying mPTP opening has long been reported [28,31,32]. Our findings; however, provide the first direct evidence for a novel effect of CsA to enhance the capacity of mitochondria to sequester $\mathrm{Ca}^{2+}$ by which it obviates $\mathrm{Ca}^{2+}$-induced $\mathrm{mPTP}$ formation. Moreover, the effect of CsA in mediating greater matrix $\mathrm{Ca}^{2+}$ buffering explains the sustained free $\left[\mathrm{Ca}^{2+}\right]_{\mathrm{m}}$ reported by Chalmers and Nicholls [14] and the CsA-induced inhibition of mitochondrial $\mathrm{Ca}^{2+}$ efflux observed in other prior studies [33,34].

\subsection{Underlying Mechanism of the CsA-Mediated $\left[\mathrm{Ca}^{2+}\right]_{m}$ Regulation}

It is well established that mitochondria are able to sequester large amounts of $\mathrm{Ca}^{2+}$, while maintaining free $\left[\mathrm{Ca}^{2+}\right]_{\mathrm{m}}$ over a range of 0.1 and $10 \mu \mathrm{M}$ depending on the $\mathrm{Ca}^{2+}$ load [14]; however, the mechanism and kinetics for this are unclear. Matrix $\mathrm{Ca}^{2+}$ buffering capacity is determined by: i) The quantity of $\mathrm{Ca}^{2+}$ that can be retained, and ii) the $\mathrm{Ca}^{2+}$ threshold level for release when $\mathrm{Ca}^{2+}$ exchangers are blocked or maximally operated [48]. The role of $\mathrm{P}_{\mathrm{i}}$ as a physiological buffer in regulation of $\left[\mathrm{Ca}^{2+}\right]_{\mathrm{m}}$ has been extensively studied $[14,44,45,49]$. The major mechanism of $\mathrm{P}_{\mathrm{i}}$-mediated $\mathrm{Ca}^{2+}$ sequestration in mitochondria is believed to be achieved by formation of amorphous $\mathrm{Ca}^{2+}-\mathrm{P}_{\mathrm{i}}$ complexes in the matrix $[48,50,51]$, which in turn maintain the free $\left[\mathrm{Ca}^{2+}\right]_{\mathrm{m}}$ at a low level. Hence, sustained $\left[\mathrm{Ca}^{2+}\right]_{\mathrm{m}}$ cyclically promotes more $\mathrm{Ca}^{2+}$ uptake via the MCU due to better preservation of both the $\mathrm{Ca}^{2+}$ gradient and $\Delta \Psi_{\mathrm{m}}$.

Though $P_{i}$ plays an essential role in matrix $\mathrm{Ca}^{2+}$ buffering, $\mathrm{P}_{\mathrm{i}}$ has also been suggested to induce mPTP opening [52]. A recent study associated $\mathrm{Ca}^{2+}-\mathrm{P}_{\mathrm{i}}$ precipitation with complex I inhibition and reduced ATP synthase rate during $\mathrm{Ca}^{2+}$ overload [53]. Another report demonstrated that increasing $\left[\mathrm{P}_{\mathrm{i}}\right]$ decreased the mitochondrial $\mathrm{Ca}^{2+}$ loading capacity [14]. It was suggested that the mPTP-sensitizing effects of $\mathrm{P}_{\mathrm{i}}$ was likely due to its effect in decreasing matrix-free $\mathrm{Mg}^{2+}$, an mPTP inhibitor [20]. In addition, formation of polyphosphate, a known inducer of $\mathrm{MPTP}$, could be a factor in regulating the $\mathrm{Ca}^{2+}$ threshold for mPTP activation [54,55]. Interestingly, two prior studies [56,57] indicated that $\mathrm{P}_{\mathrm{i}}$ is necessary for the inhibitory effect of CsA on MPTP opening. However, two other studies reported 
that CsA inhibits mPTP opening even in the absence of $P_{i}[58,59]$. Conversely, in our study, the CsA-induced enhancement of matrix $\mathrm{Ca}^{2+}$ buffering was completely annulled when both mitochondria and the experimental medium were depleted of $\mathrm{P}_{\mathrm{i}}$ (Figure 7). This loss of $\mathrm{Ca}^{2+}$ sequestration by $\mathrm{CsA}$ was reinstated when exogenous $P_{i}$ was added just before activation of the mPTP (Figure 8). These observations provide the essential explanation for the requirement of $P_{i}$ in the CsA-mediated MCBS and delay in MPTP opening.

The importance of mitochondrial matrix $\mathrm{Ca}^{2+}$ buffering via $\mathrm{P}_{\mathrm{i}}$ is underscored by the studies of Wei et al. [44,45]. They reported that $\mathrm{P}_{\mathrm{i}}$ modulates the total amount of $\mathrm{Ca}^{2+}$ uptake with smaller $\mathrm{CaCl}_{2}$ boluses, whereas $\mathrm{P}_{\mathrm{i}}$ modulates $\mathrm{Ca}^{2+}$ buffering capacity with larger $\mathrm{CaCl}_{2}$ boluses. Since we had $\mathrm{P}_{\mathrm{i}}$ in our experimental medium and the mitochondria were replete with exogenous $P_{i}$, the observation that CsA induced low ss $\left[\mathrm{Ca}^{2+}\right]_{\mathrm{e}}$ and ss $\left[\mathrm{Ca}^{2+}\right]_{\mathrm{m}}$ could be explained by the following: (i) CsA activates $\mathrm{P}_{\mathrm{i}}$-dependent matrix $\mathrm{Ca}^{2+}$ buffering potentially by maintaining the rate of $\mathrm{Ca}^{2+}-\mathrm{P}_{\mathrm{i}}$ complex formation; and (ii) CsA may activate $\mathrm{P}_{\mathrm{i}}$ transport processes (via $\mathrm{H}^{+} / \mathrm{P}_{\mathrm{i}}$ transporter and/or phosphate carrier) that help to maintain both the IMM $\mathrm{pH}_{\mathrm{m}}$ and $\Delta \Psi_{\mathrm{m}}$ gradients. These processes would limit the increase in free $\left[\mathrm{Ca}^{2+}\right]_{\mathrm{m}}$, which in turn would contribute to more $\mathrm{Ca}^{2+}$ uptake and retention by increasing the electrochemical driving force for $\mathrm{Ca}^{2+}$ influx.

\subsection{CsA vs. ADP; As a Regulator of $\left[\mathrm{Ca}^{2+}\right]_{m}$}

AdN are implicated as one of the multiple matrix factors responsible for sequestering $\mathrm{Ca}^{2+}$ by mitochondria [29,60-62]. AdN can potentiate mitochondrial $\mathrm{Ca}^{2+}$ buffering by maintaining high matrix $\mathrm{P}_{\mathrm{i}}$ concentrations that can facilitate precipitation of AdN-Ca- $\mathrm{P}_{\mathrm{i}}$ complexes, including, ATP- $\mathrm{Mg}^{2-} / \mathrm{P}_{\mathrm{i}}{ }^{2-}$ and $\mathrm{HADP}^{2-} / \mathrm{P}_{\mathrm{i}}{ }^{2-}$, and thereby increase the $\mathrm{Ca}^{2+}$ threshold for mPTP opening $[60,63]$. In a study by Carafoli et al. [60], it was reported that mitochondrial $\mathrm{Ca}^{2+}$-buffering is proportional to mitochondrial ADP uptake. In our $\mathrm{P}_{\mathrm{i}}$-replete study, $\mathrm{OMN}+\mathrm{ADP}$ had a relatively small effect on $\mathrm{Ca}^{2+}$ buffering compared to CsA, but it had a significantly larger effect than ADP or OMN alone (Figures 2, 3 and 5). A reasonable explanation could be that OMN, an ATP synthase (Complex V) inhibitor [64], could contribute towards augmenting the AdN pool and thus enhance matrix $\mathrm{Ca}^{2+}$ buffering. Consistent with our findings, a previous study also showed a greater CRC with a low-concentration of ADP with OMN compared to 10-fold larger concentration of ADP alone [30]. Thus, in agreement with Sokolova et al. [30], the observed high buffering capacity and expanded CRC with OMN+ADP is largely attributed to the ADP component of the matrix AdN pool. However, a previous study [62] reported that $\mathrm{AdN}$ also prevent mitochondrial $\mathrm{Ca}^{2+}$ influx by directly chelating $\mathrm{Ca}^{2+}$ by a Ca-ATP complexation [61]. Contrary to this observation, in our study, the direct effect of ADP on binding free $\mathrm{Ca}^{2+}$ was negligible, as assessed by adding $\mathrm{ADP}$ and $\mathrm{CaCl}_{2}$ together in mitochondria-free experimental buffer (Figure S4). Additionally, carboxyatractyloside-mediated inhibition of ADP uptake via adenine nucleotide translocase precluded matrix $\mathrm{Ca}^{2+}$ buffering and blunted the CRC by OMN+ADP or ADP alone (Figure S5). In this case, the extra-matrix ADP that accumulated did not chelate the $\mathrm{Ca}^{2+}$ added to the buffer. Altogether, these observations indicate that a direct sequestration of $\mathrm{Ca}^{2+}$ outside the mitochondria does not explain the effect of ADP alone or OMN+ADP on the enhanced CRC in our study.

A previous study [42] from our group proposed that the MCBS relies on at least two classes of $\mathrm{Ca}^{2+}$ buffers. The first class could represent classical $\mathrm{Ca}^{2+}$ buffers, including mostly metabolites (ATP, $\mathrm{ADP}$, and $\mathrm{P}_{\mathrm{i}}$ ) and mobile proteins that bind a single $\mathrm{Ca}^{2+}$ ion at a single binding site. A second class of buffers could be associated with the formation of amorphous $\mathrm{Ca}^{2+}$ phosphates, which may be capable of binding multiple $\mathrm{Ca}^{2+}$ ions at a single site in a cooperative fashion [35,38,39,42]. Genge et al. [65] showed, in an in vitro study, that annexins, a diverse class of proteins, are required for $\mathrm{Ca}^{2+}$-phosphate nucleation. Additionally, many studies have suggested an $\mathrm{AdN}$-dependent $\mathrm{Ca}^{2+}$-binding property of annexins [66]. Interestingly, mitochondria exposed to ADP alone or OMN+ADP retained their ability to maintain low ss $\left[\mathrm{Ca}^{2+}\right]_{\mathrm{e}}$ and $\mathrm{ss}\left[\mathrm{Ca}^{2+}\right]_{\mathrm{m}}$ for an extended period of cumulative $\mathrm{CaCl}_{2}$ additions, and showed a higher $\mathrm{Ca}^{2+}$ threshold for $\mathrm{mPTP}$ opening without $\mathrm{P}_{\mathrm{i}}$ compared to with $\mathrm{P}_{\mathrm{i}}$ (Figure 7). This 
extended delay in mPTP opening in the $\mathrm{P}_{\mathrm{i}}$-depleted state compared to the $\mathrm{P}_{\mathrm{i}}$-replete state reflects the ability of $P_{i}$ to induce early mPTP opening under certain conditions [52]. In this case, the presence of $\mathrm{P}_{\mathrm{i}}$ appears to counteract the ADP delay effect and induce a much earlier pore opening compared to the $\mathrm{P}_{\mathrm{i}}$-depleted state. The mechanisms for this $\mathrm{AdN}$-mediated massive matrix $\mathrm{Ca}^{2+}$ loading capacity in the absence of exogenous $P_{i}$ is unclear and needs to be further investigated. A plausible hypothesis could be that, in the absence of $\mathrm{P}_{\mathrm{i}}$, a significant $\mathrm{Ca}^{2+}$ loading capacity of AdN might be mediated via direct interaction with annexins. CsA, on the other hand, might function as a mediator that activates a $\mathrm{P}_{\mathrm{i}}$-dependent $\mathrm{Ca}^{2+}$ buffering system. Another possibility is that $\mathrm{Cyp} \mathrm{D}$, as a PPIase, reduces free phosphate levels in the matrix or blocks the $\mathrm{Ca}^{2+}$ binding property of annexins; this then would be relieved by CsA's effect to block Cyp D.

\subsection{Implication of CsA-Mediated $\mathrm{Ca}^{2+}$ Buffering on Mitochondrial Bioenergetics}

Elevated $\left[\mathrm{Ca}^{2+}\right]_{\mathrm{m}}$ over the nanomolar range is reported to increase NADH generation in part by stimulating $\mathrm{Ca}^{2+}$-sensitive dehydrogenases of the TCA cycle $[67,68]$ and activating the $\mathrm{F}_{0} \mathrm{~F}_{1}$-ATP synthase [69], thereby accelerating oxidative phosphorylation (OXPHOS). However, excess mitochondrial free $\mathrm{Ca}^{2+}$ can dissipate $\Delta \Psi_{\mathrm{m}}$ and impede OXPHOS. The IMM $\Delta \Psi_{\mathrm{m}}$ is the key factor in generating the proton motive force across the IMM; it is also one of the primary driving forces for $\mathrm{Ca}^{2+}$ uptake via the MCU [70] and triggers $\mathrm{Ca}^{2+}$ efflux via the NCLX [71,72]. Therefore, if mitochondria continue to take up $\mathrm{Ca}^{2+}$ under increased extra-matrix $\mathrm{Ca}^{2+}$ exposure, the $\mathrm{Ca}^{2+}$ would have to be buffered or ejected to prevent excess free $\left[\mathrm{Ca}^{2+}\right]_{\mathrm{m}}$ accumulation that could dissipate $\Delta \Psi_{\mathrm{m}}$ and increase oxidation of NADH.

The stability of $\mathrm{Ca}^{2+}-\mathrm{P}_{\mathrm{i}}$ precipitates inside the mitochondrial matrix largely depends on $\mathrm{pH}_{\mathrm{m}}[50]$. It is also proposed that the matrix $\left[\mathrm{P}_{\mathrm{i}}\right]$ depends on the $\mathrm{pH}$ gradient (e.g., a change in $\mathrm{pH}$ from 7 to 8 has been estimated to increase $\left[\mathrm{P}_{\mathrm{i}}\right]$ by a factor of $\left.1000[14,50]\right)$. Thus, matrix alkaline conditions could facilitate $\mathrm{Ca}^{2+}-\mathrm{P}_{\mathrm{i}}$ precipitation, whereas matrix acidification could lead to a destabilization of the $\mathrm{Ca}^{2+}-\mathrm{P}_{\mathrm{i}}$ precipitate and so enhance matrix free $\mathrm{Ca}^{2+}$ levels [14]. Consequently, we correlated the changes in $\left[\mathrm{Ca}^{2+}\right]_{\mathrm{m}}$ with indices of mitochondrial bioenergetics $\left(\Delta \Psi_{\mathrm{m}}, \mathrm{NADH}\right.$, and $\left.\mathrm{pH}\right)$ (Figure 5) to have a better understanding of the CsA-mediated MCBS. Mitochondria exposed to CsA before the repetitive $\mathrm{CaCl}_{2}$ boluses, exhibited robust mitochondrial $\mathrm{Ca}^{2+}$ uptake and rapid $\left[\mathrm{Ca}^{2+}\right]_{\mathrm{m}}$ buffering while maintaining basal $\Delta \Psi_{\mathrm{m}}, \mathrm{NADH}$, and an alkalinized $\mathrm{pH}_{\mathrm{m}}$ until mPTP opened (Figure 5). Maintaining $\Delta \Psi_{\mathrm{m}}$ during excess $\mathrm{Ca}^{2+}$ uptake in the absence of functioning NCLX suggests a strong matrix buffering effect that is induced by CsA.

In Protocol B, when CsA was added just before the onset of pore opening, NADH and $\Delta \Psi_{\mathrm{m}}$ levels transiently increased but immediately returned to baseline with each added $\mathrm{CaCl}_{2}$ bolus. This transient depolarization and NADH oxidation with each addition of $\mathrm{CaCl}_{2}$ was not observed in Protocol A. The reason for this is unclear. Nonetheless, the observed transient oxidation of NADH helped to restore $\Delta \Psi_{\mathrm{m}}$ after $\mathrm{Ca}^{2+}$ induced transient depolarization before the next $\mathrm{CaCl}_{2}$ bolus (Figure $5 \mathrm{D}, \mathrm{E}$ ). The transient redox oxidation and $\Delta \Psi_{\mathrm{m}}$ depolarization suggest that the $\mathrm{CsA}$ added at the point just before mPTP opening activated MCBS more slowly compared to Protocol A. In addition, CsA maintained the $\mathrm{pH}_{\mathrm{m}}$ gradient during prolonged $\mathrm{Ca}^{2+}$ pulse challenges (Figure $5 \mathrm{C}$ ). This finding also likely excludes a contribution of the mitochondrial calcium-hydrogen exchange (mCHE) to the $\mathrm{Ca}^{2+}$ extrusion in the absence of $\mathrm{NaCl}$. We have recently reported that CsA obviates mCHE activity at low extra-matrix $\mathrm{pH}$ [19]. However, based on our current results, it is likely that CsA triggered an enhancement of mitochondrial $\mathrm{Ca}^{2+}$ buffering so that the resulting low $\left[\mathrm{Ca}^{2+}\right]_{\mathrm{m}}$ and maintained $\Delta \Psi_{\mathrm{m}}$ and $\mathrm{pH}_{\mathrm{m}}$ accounted for the inactivity of mCHE.

\section{Conclusions}

The salient observation of this study is that CsA mitigated mPTP opening by promoting the maintenance of a low $\left[\mathrm{Ca}^{2+}\right]_{\mathrm{m}}$, by stimulating and/or potentiating MCBS. Specifically, we showed that the presence of CsA, (i) significantly delayed the MPTP opening when compared to ADP or 
OMN+ADP (Protocol A); (ii) overturned the high amplitude increase in $\left[\mathrm{Ca}^{2+}\right]_{\mathrm{m}}$ (Protocol B); (iii) maintained $\mathrm{pH}_{\mathrm{m}}$, redox state (NADH) and basal $\Delta \Psi_{\mathrm{m}}$, which maintains the driving force for more $\mathrm{Ca}^{2+}$ uptake and sequestration; and (iv) activates $\mathrm{P}_{\mathrm{i}}$-dependent mitochondrial $\mathrm{Ca}^{2+}$ sequestration to delay mPTP opening.

Our study provides a novel insight into how CsA-mediates a delay in mPTP opening by activating the MCBS, which lowers ss $\left[\mathrm{Ca}^{2+}\right]_{\mathrm{m}}$ below the threshold for mPTP activation. This concept is shown in the scheme presented in Figure 9. Our finding supports the notion that CsA facilitates $\mathrm{P}_{\mathrm{i}}$-dependent matrix $\mathrm{Ca}^{2+}$ buffering, which maintains matrix free $\mathrm{Ca}^{2+}$ and enables massive $\mathrm{Ca}^{2+}$ loading capacity, without diminishing the driving force for $\mathrm{Ca}^{2+}$ influx by maintaining $\Delta \Psi_{\mathrm{m}}$. CsA may delay mPTP opening by enhancing $\mathrm{P}_{\mathrm{i}}$-dependent matrix $\mathrm{Ca}^{2+}$ buffering and by inhibiting Cyp D [31,32]. The culmination of these two mechanisms, and possibly others not yet identified, might be responsible for CsA protection against mitochondrial $\mathrm{Ca}^{2+}$ overload. Together, these findings add to our understanding of the mechanism of CsA-mediated modulation of mPTP. Importantly, we believe that therapeutic approaches targeted at regulating $\left[\mathrm{Ca}^{2+}\right]_{\mathrm{m}}$ homeostasis represent a promising strategy to reduce cardiac injury due to $\mathrm{Ca}^{2+}$ overload by delaying $\mathrm{mPTP}$ opening and preventing induction of apoptosis.

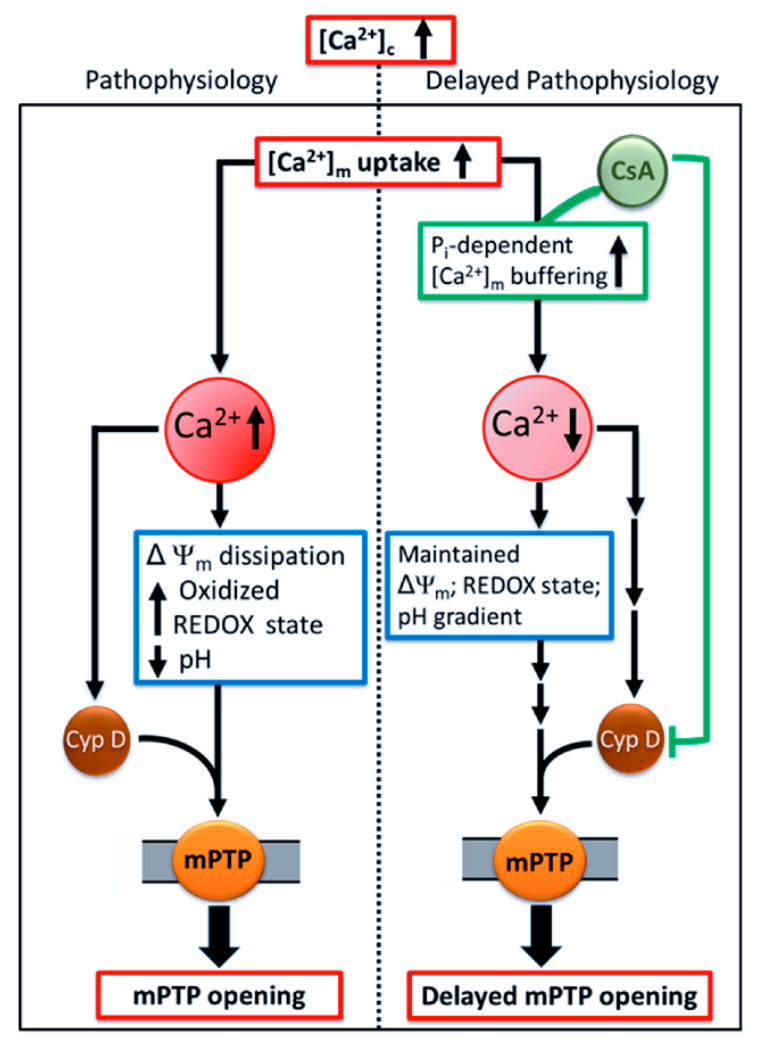

Figure 9. Schema of the potential mechanism by which CsA mediates delay in $\mathrm{Ca}^{2+}$-induced mPTP opening. Pathological conditions, like cardiac ischemia-reperfusion injury, leads to an increase in cytosolic $\mathrm{Ca}^{2+}\left(\left[\mathrm{Ca}^{2+}\right]_{\mathrm{c}}\right)$. This in turn increases $\left[\mathrm{Ca}^{2+}\right]_{\mathrm{m}}$ and generation of reactive oxygen species (ROS), impairs respiration and substrate utilization, and leads to uncoupling of oxidative phosphorylation. Lower $\Delta \Psi_{\mathrm{m}}$, oxidized redox state, and dissipation of the $\mathrm{pH}_{\mathrm{m}}$ gradient, together induces $\mathrm{mPTP}$ opening which triggers apoptosis. These detrimental consequences that underlie IR injury could be mollified by CsA, which allows the mitochondria to maintain their basal $\left[\mathrm{Ca}^{2+}\right]_{\mathrm{m}}$ via enhanced $\mathrm{P}_{\mathrm{i}}$-dependent matrix $\mathrm{Ca}^{2+}$ buffering, in addition to, or through, Cyp D inhibition. Sustained low $\left[\mathrm{Ca}^{2+}\right]_{\mathrm{m}}$ maintains mitochondrial integrity and function and delays mPTP opening. 
Supplementary Materials: The following are available online at http://www.mdpi.com/2073-4409/8/9/1052/s1. Figure S1: Quantification of calcium retention capacity (CRC) for each treatment, DMSO (control), ADP, oligomycin $(\mathrm{OMN}), \mathrm{OMN}+\mathrm{ADP}$, and CsA during Protocol A (A) and Protocol B (B). Figure S2: Average $\mathrm{Ca}^{2+}$ added before mPTP opening, $\Delta \Psi_{\mathrm{m}}$ collapse, NADH oxidation, and matrix acidification. Figure S3: Trend-fits for calculation of buffering rate. Figure S4: Fura-4F ratio representing the change in $\left[\mathrm{Ca}^{2+}\right]_{\mathrm{e}}$ before and after adding a $20 \mu \mathrm{M}$ $\mathrm{CaCl}_{2}$ bolus in the absence or presence of $250 \mu \mathrm{M}$ ADP in the mitochondria-free experimental buffer. Figure S5: Representative raw traces of extra-matrix $\mathrm{Ca}^{2+}$ fluorescence (Fura-4F ratio) and $\mathrm{Ca}^{2+}$ uptake in mitochondria pretreated with $0.5 \%$ DMSO (control), OMN+ADP, and CATR (carboxyatractyloside)+OMN+ADP prior to mPTP opening.

Author Contributions: J.M. and A.K.S.C., conceptualized and designed the experiments; J.M. and A.J.D., performed experiments; J.M., A.J.D. and G.K.N., analyzed data; J.M., W.-M.K., D.F.S. and A.K.S.C., interpreted results; J.M. and A.K.S.C., drafted the manuscript and figures; J.M., G.K.N., W.-M.K., D.F.S. and A.K.S.C., critically read/edited the manuscript. All authors have read and approved the manuscript.

Funding: This project was supported by the Veterans Administration (Merit Review BX-002539-01).

Acknowledgments: The authors are thankful to James S. Heisner for technical assistance.

Conflicts of Interest: The authors declare no conflicts of interest.

\section{References}

1. Denton, R.M.; McCormack, J.G. The calcium sensitive dehydrogenases of vertebrate mitochondria. Cell Calcium 1986, 7, 377-386. [CrossRef]

2. Jouaville, L.S.; Pinton, P.; Bastianutto, C.; Rutter, G.A.; Rizzuto, R. Regulation of mitochondrial ATP synthesis by calcium: Evidence for a long-term metabolic priming. Proc. Natl. Acad. Sci. USA 1999, 96, 13807-13812. [CrossRef] [PubMed]

3. Bernardi, P. Mitochondrial transport of cations: Channels, exchangers, and permeability transition. Physiol. Rev. 1999, 79, 1127-1155. [CrossRef] [PubMed]

4. Hajnoczky, G.; Csordas, G.; Das, S.; Garcia-Perez, C.; Saotome, M.; Sinha Roy, S.; Yi, M. Mitochondrial calcium signalling and cell death: Approaches for assessing the role of mitochondrial Ca2+ uptake in apoptosis. Cell Calcium 2006, 40, 553-560. [CrossRef] [PubMed]

5. Brookes, P.S.; Yoon, Y.; Robotham, J.L.; Anders, M.W.; Sheu, S.S. Calcium, ATP, and ROS: A mitochondrial love-hate triangle. Am. J. Physiol. Cell Physiol. 2004, 287, C817-C833. [CrossRef] [PubMed]

6. O'Rourke, B.; Cortassa, S.; Aon, M.A. Mitochondrial ion channels: Gatekeepers of life and death. Physiology (Bethesda) 2005, 20, 303-315. [CrossRef]

7. Camara, A.K.; Lesnefsky, E.J.; Stowe, D.F. Potential therapeutic benefits of strategies directed to mitochondria. Antioxid. Redox Signal. 2010, 13, 279-347. [CrossRef]

8. Gunter, T.E.; Buntinas, L.; Sparagna, G.; Eliseev, R.; Gunter, K. Mitochondrial calcium transport: Mechanisms and functions. Cell Calcium 2000, 28, 285-296. [CrossRef]

9. Baughman, J.M.; Perocchi, F.; Girgis, H.S.; Plovanich, M.; Belcher-Timme, C.A.; Sancak, Y.; Bao, X.R.; Strittmatter, L.; Goldberger, O.; Bogorad, R.L.; et al. Integrative genomics identifies MCU as an essential component of the mitochondrial calcium uniporter. Nature 2011, 476, 341-345. [CrossRef]

10. De Stefani, D.; Raffaello, A.; Teardo, E.; Szabo, I.; Rizzuto, R. A forty-kilodalton protein of the inner membrane is the mitochondrial calcium uniporter. Nature 2011, 476, 336-340. [CrossRef]

11. Mitchell, P. Coupling of phosphorylation to electron and hydrogen transfer by a chemi-osmotic type of mechanism. Nature 1961, 191, 144-148. [CrossRef] [PubMed]

12. Mitchell, P. Keilin's respiratory chain concept and its chemiosmotic consequences. Science 1979, 206, 1148-1159. [CrossRef] [PubMed]

13. Greenawalt, J.W.; Rossi, C.S.; Lehninger, A.L. Effect of Active Accumulation of Calcium and Phosphate Ions on the Structure of Rat Liver Mitochondria. J. Cell Biol. 1964, 23, 21-38. [CrossRef] [PubMed]

14. Chalmers, S.; Nicholls, D.G. The relationship between free and total calcium concentrations in the matrix of liver and brain mitochondria. J. Biol. Chem. 2003, 278, 19062-19070. [CrossRef] [PubMed]

15. Starkov, A.A. The molecular identity of the mitochondrial Ca2+ sequestration system. FEBS J. 2010, 277, 3652-3663. [CrossRef]

16. Carafoli, E.; Tiozzo, R.; Lugli, G.; Crovetti, F.; Kratzing, C. The release of calcium from heart mitochondria by sodium. J. Mol. Cell. Cardiol. 1974, 6, 361-371. [CrossRef] 
17. Palty, R.; Silverman, W.F.; Hershfinkel, M.; Caporale, T.; Sensi, S.L.; Parnis, J.; Nolte, C.; Fishman, D.; Shoshan-Barmatz, V.; Herrmann, S.; et al. NCLX is an essential component of mitochondrial Na+/Ca2+ exchange. Proc. Natl. Acad. Sci. USA 2010, 107, 436-441. [CrossRef]

18. Boyman, L.; Williams, G.S.; Khananshvili, D.; Sekler, I.; Lederer, W.J. NCLX: The mitochondrial sodium calcium exchanger. J. Mol. Cell. Cardiol. 2013, 59, 205-213. [CrossRef]

19. Haumann, J.; Camara, A.K.S.; Gadicherla, A.K.; Navarro, C.D.; Boelens, A.D.; Blomeyer, C.A.; Dash, R.K.; Boswell, M.R.; Kwok, W.M.; Stowe, D.F. Slow $\mathrm{Ca}(2+)$ Efflux by $\mathrm{Ca}(2+) / \mathrm{H}(+)$ Exchange in Cardiac Mitochondria Is Modulated by $\mathrm{Ca}(2+)$ Re-uptake via MCU, Extra-Mitochondrial $\mathrm{pH}$, and $\mathrm{H}(+)$ Pumping by FOF1-ATPase. Front. Physiol. 2018, 9, 1914. [CrossRef]

20. Bernardi, P.; Vassanelli, S.; Veronese, P.; Colonna, R.; Szabo, I.; Zoratti, M. Modulation of the mitochondrial permeability transition pore. Effect of protons and divalent cations. J. Biol. Chem. 1992, 267, 2934-2939.

21. Szabo, I.; Zoratti, M. The mitochondrial megachannel is the permeability transition pore. J. Bioenerg. Biomembr. 1992, 24, 111-117. [CrossRef] [PubMed]

22. Crompton, M. The mitochondrial permeability transition pore and its role in cell death. Biochem. J. 1999, 341 Pt 2, 233-249. [CrossRef] [PubMed]

23. Kim, J.S.; He, L.; Lemasters, J.J. Mitochondrial permeability transition: A common pathway to necrosis and apoptosis. Biochem. Biophys. Res. Commun. 2003, 304, 463-470. [CrossRef]

24. Nakagawa, T.; Shimizu, S.; Watanabe, T.; Yamaguchi, O.; Otsu, K.; Yamagata, H.; Inohara, H.; Kubo, T.; Tsujimoto, Y. Cyclophilin D-dependent mitochondrial permeability transition regulates some necrotic but not apoptotic cell death. Nature 2005, 434, 652-658. [CrossRef] [PubMed]

25. Basso, E.; Fante, L.; Fowlkes, J.; Petronilli, V.; Forte, M.A.; Bernardi, P. Properties of the permeability transition pore in mitochondria devoid of Cyclophilin, D. J. Biol. Chem. 2005, 280, 18558-18561. [CrossRef] [PubMed]

26. Baines, C.P.; Kaiser, R.A.; Purcell, N.H.; Blair, N.S.; Osinska, H.; Hambleton, M.A.; Brunskill, E.W.; Sayen, M.R.; Gottlieb, R.A.; Dorn, G.W.; et al. Loss of cyclophilin D reveals a critical role for mitochondrial permeability transition in cell death. Nature 2005, 434, 658-662. [CrossRef]

27. Hunter, D.R.; Haworth, R.A. The Ca2+-induced membrane transition in mitochondria. I. The protective mechanisms. Arch. Biochem. Biophys. 1979, 195, 453-459. [CrossRef]

28. Halestrap, A.P.; Connern, C.P.; Griffiths, E.J.; Kerr, P.M. Cyclosporin A binding to mitochondrial cyclophilin inhibits the permeability transition pore and protects hearts from ischaemia/reperfusion injury. Mol. Cell. Biochem. 1997, 174, 167-172. [CrossRef]

29. Haumann, J.; Dash, R.K.; Stowe, D.F.; Boelens, A.D.; Beard, D.A.; Camara, A.K. Mitochondrial free [Ca2+] increases during ATP/ADP antiport and ADP phosphorylation: Exploration of mechanisms. Biophys. J. 2010, 99, 997-1006. [CrossRef]

30. Sokolova, N.; Pan, S.; Provazza, S.; Beutner, G.; Vendelin, M.; Birkedal, R.; Sheu, S.S. ADP protects cardiac mitochondria under severe oxidative stress. PLoS ONE 2013, 8, e83214. [CrossRef]

31. Griffiths, E.J.; Halestrap, A.P. Further evidence that cyclosporin A protects mitochondria from calcium overload by inhibiting a matrix peptidyl-prolyl cis-trans isomerase. Implications for the immunosuppressive and toxic effects of cyclosporin. Biochem. J. 1991, 274 Pt 2, 611-614. [CrossRef] [PubMed]

32. Waldmeier, P.C.; Feldtrauer, J.J.; Qian, T.; Lemasters, J.J. Inhibition of the mitochondrial permeability transition by the nonimmunosuppressive cyclosporin derivative NIM811. Mol. Pharmacol. 2002, 62, 22-29. [CrossRef]

33. Altschuld, R.A.; Hohl, C.M.; Castillo, L.C.; Garleb, A.A.; Starling, R.C.; Brierley, G.P. Cyclosporin inhibits mitochondrial calcium efflux in isolated adult rat ventricular cardiomyocytes. Am. J. Physiol. 1992, 262, H1699-H1704. [CrossRef]

34. Wei, A.C.; Liu, T.; Cortassa, S.; Winslow, R.L.; O’Rourke, B. Mitochondrial Ca2+ influx and efflux rates in guinea pig cardiac mitochondria: Low and high affinity effects of cyclosporine A. Biochim. Biophys. Acta 2011, 1813, 1373-1381. [CrossRef] [PubMed]

35. Blomeyer, C.A.; Bazil, J.N.; Stowe, D.F.; Pradhan, R.K.; Dash, R.K.; Camara, A.K. Dynamic buffering of mitochondrial Ca2+ during Ca2+ uptake and $\mathrm{Na}+$-induced $\mathrm{Ca} 2+$ release. J. Bioenerg. Biomembr. 2013, 45, 189-202. [CrossRef] [PubMed]

36. Aldakkak, M.; Stowe, D.F.; Dash, R.K.; Camara, A.K. Mitochondrial handling of excess Ca2+ is substrate-dependent with implications for reactive oxygen species generation. Free Radic. Biol. Med. 2013, 56, 193-203. [CrossRef] [PubMed] 
37. Agarwal, B.; Dash, R.K.; Stowe, D.F.; Bosnjak, Z.J.; Camara, A.K. Isoflurane modulates cardiac mitochondrial bioenergetics by selectively attenuating respiratory complexes. Biochim. Biophys. Acta 2014, 1837, $354-365$. [CrossRef] [PubMed]

38. Blomeyer, C.A.; Bazil, J.N.; Stowe, D.F.; Dash, R.K.; Camara, A.K. Mg(2+) differentially regulates two modes of mitochondrial $\mathrm{Ca}(2+)$ uptake in isolated cardiac mitochondria: Implications for mitochondrial $\mathrm{Ca}(2+)$ sequestration. J. Bioenerg. Biomembr. 2016, 48, 175-188. [CrossRef]

39. Boelens, A.D.; Pradhan, R.K.; Blomeyer, C.A.; Camara, A.K.; Dash, R.K.; Stowe, D.F. Extra-matrix Mg2+ limits $\mathrm{Ca} 2+$ uptake and modulates $\mathrm{Ca} 2+$ uptake-independent respiration and redox state in cardiac isolated mitochondria. J. Bioenerg. Biomembr. 2013, 45, 203-218. [CrossRef]

40. Scaduto, R.C., Jr.; Grotyohann, L.W. Measurement of mitochondrial membrane potential using fluorescent rhodamine derivatives. Biophys. J. 1999, 76, 469-477. [CrossRef]

41. Grynkiewicz, G.; Poenie, M.; Tsien, R.Y. A new generation of Ca2+ indicators with greatly improved fluorescence properties. J. Biol. Chem. 1985, 260, 3440-3450. [PubMed]

42. Bazil, J.N.; Blomeyer, C.A.; Pradhan, R.K.; Camara, A.K.; Dash, R.K. Modeling the calcium sequestration system in isolated guinea pig cardiac mitochondria. J. Bioenerg. Biomembr. 2013, 45, 177-188. [CrossRef] [PubMed]

43. Zoccarato, F.; Nicholls, D. The role of phosphate in the regulation of the independent calcium-efflux pathway of liver mitochondria. Eur. J. Biochem. 1982, 127, 333-338. [CrossRef] [PubMed]

44. Wei, A.C.; Liu, T.; O’Rourke, B. Dual Effect of Phosphate Transport on Mitochondrial Ca2+ Dynamics. J. Biol. Chem. 2015, 290, 16088-16098. [CrossRef] [PubMed]

45. Wei, A.C.; Liu, T.; Winslow, R.L.; O’Rourke, B. Dynamics of matrix-free Ca2+ in cardiac mitochondria: Two components of Ca2+ uptake and role of phosphate buffering. J. Gen. Physiol. 2012, 139, 465-478. [CrossRef] [PubMed]

46. Glancy, B.; Balaban, R.S. Role of mitochondrial Ca2+ in the regulation of cellular energetics. Biochemistry 2012, 51, 2959-2973. [CrossRef] [PubMed]

47. Vasington, F.D.; Murphy, J.V. Ca ion uptake by rat kidney mitochondria and its dependence on respiration and phosphorylation. J. Biol. Chem. 1962, 237, 2670-2677. [PubMed]

48. Chinopoulos, C.; Adam-Vizi, V. Mitochondrial Ca2+ sequestration and precipitation revisited. FEBS J. 2010, 277, 3637-3651. [CrossRef] [PubMed]

49. Harris, E.J.; Zaba, B. The phosphate requirement for Ca2+-uptake by heart and liver mitochondria. FEBS Lett. 1977, 79, 284-290. [CrossRef]

50. Nicholls, D.G.; Chalmers, S. The integration of mitochondrial calcium transport and storage. J. Bioenerg. Biomembr. 2004, 36, 277-281. [CrossRef]

51. Kristian, T.; Pivovarova, N.B.; Fiskum, G.; Andrews, S.B. Calcium-induced precipitate formation in brain mitochondria: Composition, calcium capacity, and retention. J. Neurochem. 2007, 102, 1346-1356. [CrossRef]

52. Kushnareva, Y.E.; Haley, L.M.; Sokolove, P.M. The role of low ( $<$ or $=1 \mathrm{mM})$ phosphate concentrations in regulation of mitochondrial permeability: Modulation of matrix free Ca2+ concentration. Arch. Biochem. Biophys. 1999, 363, 155-162. [CrossRef] [PubMed]

53. Malyala, S.; Zhang, Y.; Strubbe, J.O.; Bazil, J.N. Calcium phosphate precipitation inhibits mitochondrial energy metabolism. PLoS Comput. Biol. 2019, 15, e1006719. [CrossRef] [PubMed]

54. Abramov, A.Y.; Fraley, C.; Diao, C.T.; Winkfein, R.; Colicos, M.A.; Duchen, M.R.; French, R.J.; Pavlov, E. Targeted polyphosphatase expression alters mitochondrial metabolism and inhibits calcium-dependent cell death. Proc. Natl. Acad. Sci. USA 2007, 104, 18091-18096. [CrossRef]

55. Seidlmayer, L.K.; Gomez-Garcia, M.R.; Blatter, L.A.; Pavlov, E.; Dedkova, E.N. Inorganic polyphosphate is a potent activator of the mitochondrial permeability transition pore in cardiac myocytes. J. Gen. Physiol. 2012, 139, 321-331. [CrossRef]

56. Chavez, E.; Moreno-Sanchez, R.; Zazueta, C.; Rodriguez, J.S.; Bravo, C.; Reyes-Vivas, H. On the protection by inorganic phosphate of calcium-induced membrane permeability transition. J. Bioenerg. Biomembr. 1997, 29, 571-577. [CrossRef] [PubMed]

57. Basso, E.; Petronilli, V.; Forte, M.A.; Bernardi, P. Phosphate is essential for inhibition of the mitochondrial permeability transition pore by cyclosporin A and by cyclophilin D ablation. J. Biol. Chem. 2008, 283, 26307-26311. [CrossRef] [PubMed] 
58. McGee, A.M.; Baines, C.P. Phosphate is not an absolute requirement for the inhibitory effects of cyclosporin A or cyclophilin D deletion on mitochondrial permeability transition. Biochem. J. 2012, 443, 185-191. [CrossRef]

59. Varanyuwatana, P.; Halestrap, A.P. The roles of phosphate and the phosphate carrier in the mitochondrial permeability transition pore. Mitochondrion 2012, 12, 120-125. [CrossRef]

60. Carafoli, E.; Rossi, C.S.; Lehninger, A.L. Uptake of Adenine Nucleotides by Respiring Mitochondria during Active Accumulation of Ca++ and Phosphate. J. Biol. Chem. 1965, 240, 2254-2261.

61. Michailova, A.; McCulloch, A. Model study of ATP and ADP buffering, transport of $\mathrm{Ca}(2+)$ and $\mathrm{Mg}(2+)$, and regulation of ion pumps in ventricular myocyte. Biophys. J. 2001, 81, 614-629. [CrossRef]

62. Litsky, M.L.; Pfeiffer, D.R. Regulation of the mitochondrial Ca2+ uniporter by external adenine nucleotides: The uniporter behaves like a gated channel which is regulated by nucleotides and divalent cations. Biochemistry 1997, 36, 7071-7080. [CrossRef] [PubMed]

63. Traba, J.; Del Arco, A.; Duchen, M.R.; Szabadkai, G.; Satrustegui, J. SCaMC-1 promotes cancer cell survival by desensitizing mitochondrial permeability transition via ATP/ADP-mediated matrix $\mathrm{Ca}(2+)$ buffering. Cell Death Differ. 2012, 19, 650-660. [CrossRef] [PubMed]

64. Devenish, R.J.; Prescott, M.; Boyle, G.M.; Nagley, P. The oligomycin axis of mitochondrial ATP synthase: OSCP and the proton channel. J. Bioenerg. Biomembr. 2000, 32, 507-515. [CrossRef] [PubMed]

65. Genge, B.R.; Wu, L.N.; Wuthier, R.E. In vitro modeling of matrix vesicle nucleation: Synergistic stimulation of mineral formation by annexin A5 and phosphatidylserine. J. Biol. Chem. 2007, 282, 26035-26045. [CrossRef] [PubMed]

66. Bandorowicz-Pikula, J.; Buchet, R.; Pikula, S. Annexins as nucleotide-binding proteins: Facts and speculations. Bioessays 2001, 23, 170-178. [CrossRef]

67. McCormack, J.G.; Denton, R.M. Intracellular calcium ions and intramitochondrial Ca2+ in the regulation of energy metabolism in mammalian tissues. Proc. Nutr. Soc. 1990, 49, 57-75. [CrossRef] [PubMed]

68. Rutter, G.A. Ca2(+)-binding to citrate cycle dehydrogenases. Int. J. Biochem. 1990, 22, 1081-1088. [CrossRef]

69. Territo, P.R.; Mootha, V.K.; French, S.A.; Balaban, R.S. Ca(2+) activation of heart mitochondrial oxidative phosphorylation: Role of the F(0)/F(1)-ATPase. Am. J. Physiol. Cell Physiol. 2000, 278, C423-C435. [CrossRef] [PubMed]

70. Chinopoulos, C.; Adam-Vizi, V. The 'ins and outs' of Ca2+ in mitochondria. FEBS J. 2010, $277,3621$. [CrossRef] [PubMed]

71. Jung, D.W.; Baysal, K.; Brierley, G.P. The sodium-calcium antiport of heart mitochondria is not electroneutral. J. Biol. Chem. 1995, 270, 672-678. [CrossRef] [PubMed]

72. Kim, B.; Matsuoka, S. Cytoplasmic Na+-dependent modulation of mitochondrial Ca2+ via electrogenic mitochondrial Na+-Ca2+ exchange. J. Physiol. 2008, 586, 1683-1697. [CrossRef] [PubMed] 